\title{
Temperature as a modulator of sexual selection
}

\author{
Roberto García-Roa ${ }^{1}$, Francisco Garcia-Gonzalez ${ }^{2,3}$, Daniel W.A. Noble ${ }^{4,5}$ and \\ Pau Carazo ${ }^{1 *}$ [] \\ ${ }^{1}$ Behaviour and Evolution, Ethology Lab, Cavanilles Institute of Biodiversity and Evolutionary Biology, University of Valencia, C/Catedrático Fosé \\ Beltrán 2, Paterna, Valencia, 46980, Spain \\ ${ }^{2}$ Doñana Biological Station, Spanish Research Council CSIC, c/Americo Vespucio, 26, Isla de la Cartuja, Sevilla, 41092, Spain \\ ${ }^{3}$ Centre for Evolutionary Biology, School of Biological Sciences, The University of Western Australia, 35 Stirling Highway, Crawley, \\ Western Australia, 6009, Australia \\ ${ }^{4}$ Ecology and Evolution Research Centre, School of Biological, Earth and Environmental Sciences, University of New South Wales, Sydney, \\ New South Wales, 2052, Australia \\ ${ }^{5}$ Division of Ecology and Evolution, Research School of Biology, The Australian National University, Canberra, Australian Capital Territory, 2061, \\ Australia
}

\begin{abstract}
A central question in ecology and evolution is to understand why sexual selection varies so much in strength across taxa; it has long been known that ecological factors are crucial to this. Temperature is a particularly salient abiotic ecological factor that modulates a wide range of physiological, morphological and behavioural traits, impacting individuals and populations at a global taxonomic scale. Furthermore, temperature exhibits substantial temporal variation (e.g. daily, seasonally and inter-seasonally), and hence for most species in the wild sexual selection will regularly unfold in a dynamic thermal environment. Unfortunately, studies have so far almost completely neglected the role of temperature as a modulator of sexual selection. Here, we outline the main pathways through which temperature can affect the intensity and form (i.e. mechanisms) of sexual selection, via: (i) direct effects on secondary sexual traits and preferences (i.e. trait variance, opportunity for selection and trait-fitness covariance), and (ii) indirect effects on key mating parameters, sex-specific reproductive costs/benefits, trade-offs, demography and correlated abiotic factors. Building upon this framework, we show that, by focusing exclusively on the first-order effects that environmental temperature has on traits linked with individual fitness and population viability, current global warming studies may be ignoring eco-evolutionary feedbacks mediated by sexual selection. Finally, we tested the general prediction that temperature modulates sexual selection by conducting a meta-analysis of available studies experimentally manipulating temperature and reporting effects on the variance of male/female reproductive success and/or traits under sexual selection. Our results show a clear association between temperature and sexual selection measures in both sexes. In short, we suggest that studying the feedback between temperature and sexual selection processes may be vital to developing a better understanding of variation in the strength of sexual selection in nature, and its consequences for population viability in response to environmental change (e.g. global warming).
\end{abstract}

Key words: sexual selection, temperature, sexual conflict, rapid environmental change, population viability, meta-analysis

\section{CONTENTS}

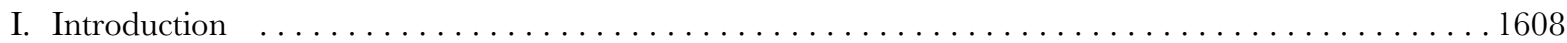

II. Framework for the study of temperature and sexual selection $\ldots \ldots \ldots \ldots \ldots \ldots \ldots \ldots \ldots \ldots \ldots$

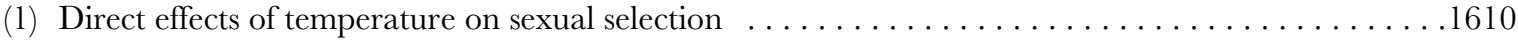

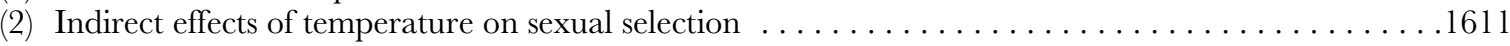

* Address for correspondence (Tel: +34 963544051; E-mail: pau.carazo@uv.es) 
III. Specific pathways for temperature effects on sexual selection $\ldots \ldots \ldots \ldots \ldots 16 \ldots \ldots \ldots$

(1) Temperature effects on secondary sexual traits and associated preferences $\ldots \ldots \ldots \ldots 11$

(a) Behaviour, physiology and life-history traits related to sexual selection $\ldots \ldots \ldots 1611$

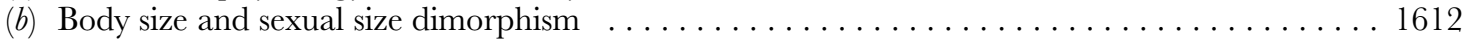

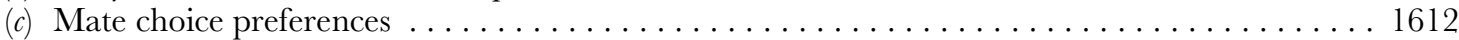

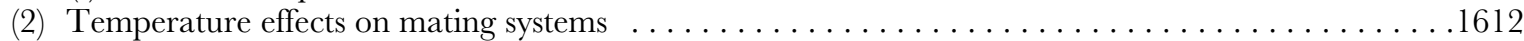

(3) Temperature effects on sex-specific costs/benefits of reproduction $\ldots \ldots \ldots \ldots \ldots \ldots$

(4) Temperature effects on constraints and trade-offs $\ldots \ldots \ldots \ldots \ldots \ldots \ldots \ldots \ldots$

(5) Temperature effects on population dynamics/demographics $\ldots \ldots \ldots \ldots \ldots \ldots 13$

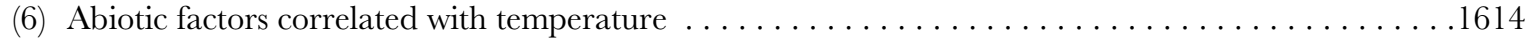

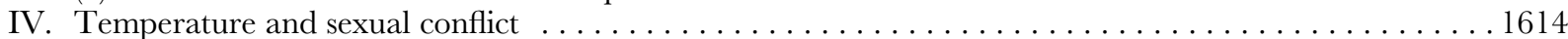

(1) Temperature effects on inter-locus sexual conflict $\ldots \ldots \ldots \ldots \ldots \ldots \ldots \ldots \ldots \ldots$

(2) Temperature effects on intra-locus sexual conflict $\ldots \ldots \ldots \ldots \ldots \ldots \ldots \ldots \ldots \ldots$

V. Temperature, sexual selection and rapid environmental change $\ldots \ldots \ldots \ldots \ldots 16$

VI. Processes involved in effects of temperature on sexual selection $\ldots \ldots \ldots \ldots \ldots 16$

VII. Meta-analysis: experimental evidence that temperature impacts sexual selection $\ldots \ldots \ldots \ldots 17$

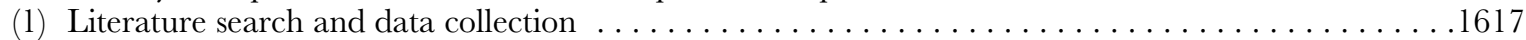

(2) Effect size statistics - comparing variance in fitness $\ldots \ldots \ldots \ldots \ldots \ldots \ldots \ldots \ldots \ldots$

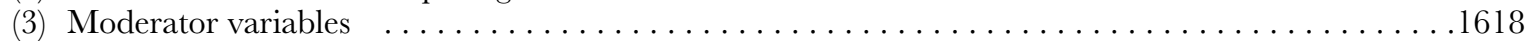

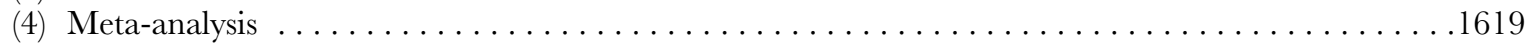

(5) Meta-analysis results and discussion $\ldots \ldots \ldots \ldots \ldots \ldots \ldots \ldots \ldots \ldots \ldots \ldots$

VIII. The path ahead: studying the interplay between temperature, sexual selection and population viability 1620

(1) Considering temperature effects on sexual selection $\ldots \ldots \ldots \ldots \ldots \ldots \ldots \ldots \ldots$

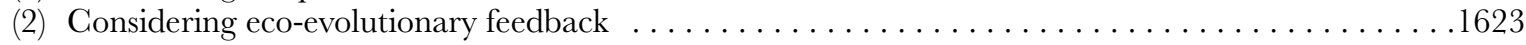

(3) Where and how to study temperature effects on sexual selection $\ldots \ldots \ldots \ldots \ldots \ldots \ldots$

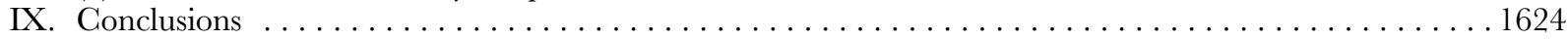

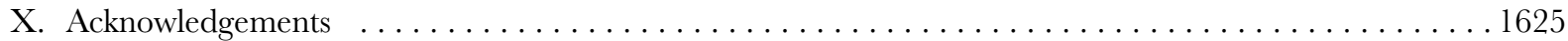

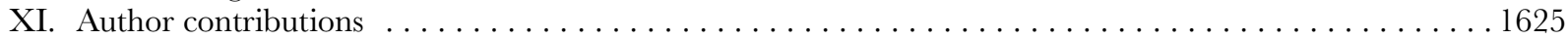

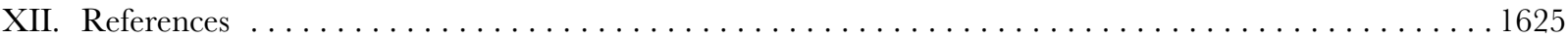

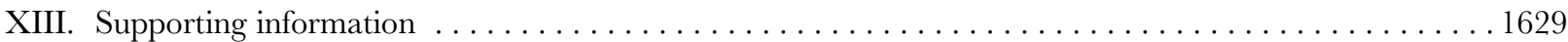

\section{INTRODUGTION}

Sexual selection is the process whereby organisms evolve to be better competitors in their struggle for reproductive opportunities. Since Darwin's formulation (Darwin, 1871), it has become a cornerstone to understand the evolution of male and female adaptations and life histories (Andersson, 1994), speciation (Janicke et al., 2018), and the maintenance of sexual reproduction itself (Agrawal, 2001). Precisely due to its central role in evolutionary theory, we have also come to understand that sexual selection is an equally important determinant of population viability and evolvability, and thus of a population's capacity to withstand environmental change (Pomiankowski \& Moller, 1995; Cally, Stuart-Fox, \& Holman, 2019). Indeed, sexual selection is a potent mechanism by which the genome can be purged of deleterious mutations (Radwan, 2004; Whitlock \& Agrawal, 2009) and, in so doing, effectively protect populations against extinction (Jarzebowska \& Radwan, 2010; Lumley et al., 2015). Sexual selection has been shown to increase the rate of adaptation in traits under both sexual and natural selection via 'genic capture' (Rowe \& Houle, 1996; Lorch et al., 2003), a process presumed to be particularly effective in response to directional environmental change (Long, Agrawal, \& Rowe, 2012; Martinez-Ruiz \& Knell, 2017; Parrett \& Knell, 2018). Given the relevance of sexual selection for individual phenotypes and the fate of populations (Cally et al., 2019), a central question in evolutionary biology is to disentangle why sexual selection varies so much in its form, strength and outcomes across taxa.

We have long realised that ecological factors are relevant to understanding the operation of sexual selection (Emlen \& Oring, 1977; Maan \& Seehausen, 2011) and sexual conflict (Rowe et al., 1994; Arbuthnott et al., 2014; Berger et al., 2014; Perry, Garroway, \& Rowe, 2017; Perry \& Rowe, 2018; García-Roa, Chirinos, \& Carazo, 2019). Despite the fact that studies on the factors governing ecoevolutionary interactions are still scarce (Svensson, 2019), there is increasing evidence that sexual selection frequently fluctuates with changing environmental conditions (Cornwallis \& Uller, 2010; Miller \& Svensson, 2014; Evans \& Garcia-Gonzalez, 2016). For example, the strength and direction of sexual selection can vary with resource quality and availability (Gwynne \& Simmons, 1990; Gillespie et al., 2014), population density (Kokko \& Rankin, 2006), or sex ratio (Punzalan, Rodd, \& Rowe, 2010), amongst others (Miller \& Svensson, 2014). Surprisingly, however, while there is ample evidence that temperature strongly impacts organism physiology, metabolism, morphology and behaviour, its role in relation to sexual selection and sexual conflict has mostly been neglected. There is good evidence that sexual selection can influence the capacity of a population to 
withstand environmental change in the form of rising temperatures (Plesnar-Bielak et al., 2012; Miller \& Svensson, 2014; Parrett \& Knell, 2018), but we know very little about how temperature affects sexual selection.

In particular, only a handful of studies have tackled the role of temperature fluctuations at an ecologically relevant temporal (i.e. circadian, seasonal, or inter-seasonal) and/or spatial (i.e. micro- and macrogeographic) scale. In the worm pipefish (Nerophis lumbriciformis) sexual selection seems to be stronger in warm waters (Monteiro \& Lyons, 2012), and there is significant co-variation between water temperature and several potential indicators of sexual selection intensity (e.g. sexual size dimorphism) across populations along a thermal cline (Monteiro et al., 2017). Temperature has also been shown to disrupt mating patterns in artemia (Artemia franciscana), ultimately modulating sexual selection intensity (Santos, Vieira, \& Monteiro, 2018). In grey seals (Halichoerus grypus), changes in local weather conditions affect the degree of polygyny and hence the opportunity for selection (Twiss et al., 2007). Similarly, a decade-long study in a population of free-ranging sand lizards (Lacerta agilis) reported that elevated temperatures correlated with an increase in the degree of polygyny, number of sires per clutch, and the opportunity for post-copulatory sexual selection (Olsson et al., 2011). In the cigarette beetle (Lasioderma serricorne), thermal conditions affect post-copulatory, but not pre-copulatory, traits. This is bound to change the relative weight of (and covariance between) these two episodes of sexual selection which, in turn, will determine the nature and total opportunity for sexual selection (Suzaki et al., 2018). While tantalising results, studies so far have provided preliminary and mostly indirect support for the idea that temperature can modulate sexual selection across taxa. Much of the attention has focused on understanding the direct consequences of abrupt temperature shifts (e.g. stressful/extreme events) on organism fitness and population viability. However, most organisms are reproductively active across a relatively wide range of temperatures in the wild, which means intra- and inter-sexual selection will normally unfold in a constantly fluctuating thermal environment. This contrasts starkly with the constant temperature conditions under which most sexual selection research has been (and still is) currently conducted in the laboratory. To conclude, we know surprisingly little about: (i) whether and how temperature fluctuations might modulate the form and strength of sexual selection, and (ii) whether and how this may lead to eco-evolutionary feedback, and hence affect population viability. The overarching aim of this review is to knit together existing theory to provide a comprehensive conceptual framework for how and why temperature effects on organisms may modulate sexual selection (Fig. 1), and hopefully stimulate further study on this area of research.

\section{FRAMEWORK FOR THE STUDY OF TEMPERATURE AND SEXUAL SELEGTION}

There is a fundamental reason why temperature may be a particularly salient ecological determinant of sexual
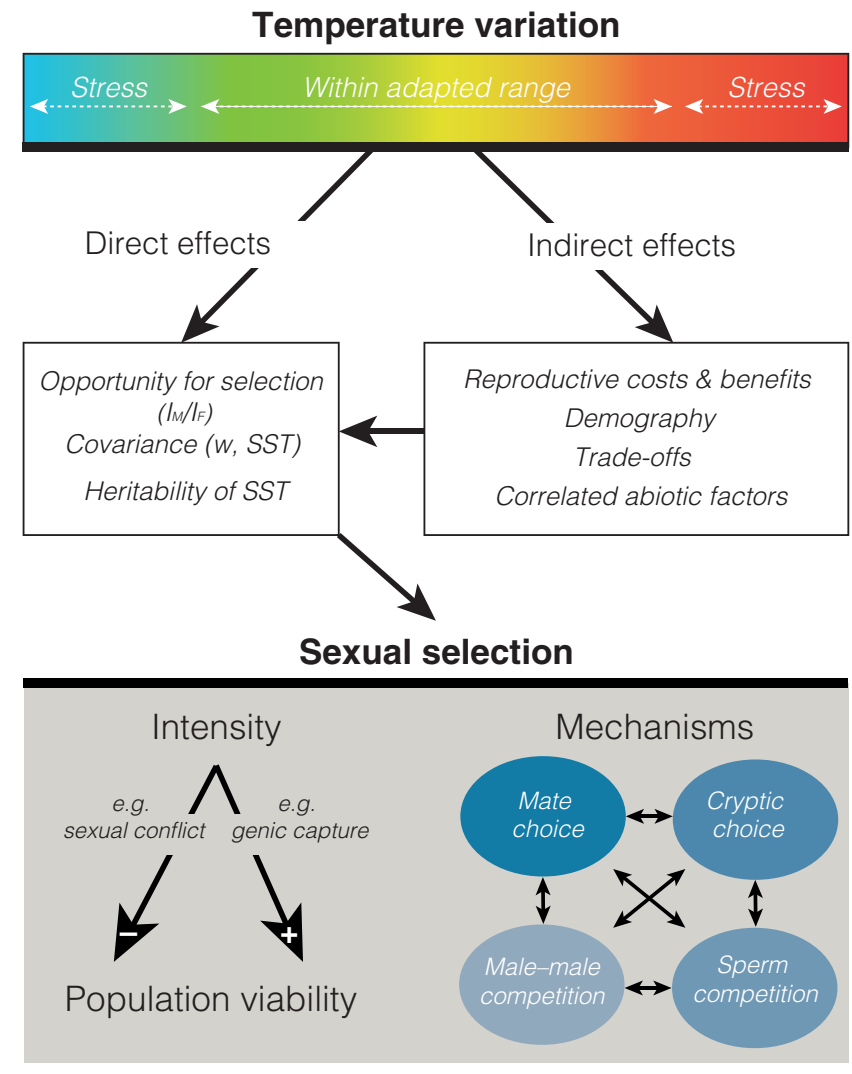

Fig 1. A schematic outline of pathways by which temperature can affect sexual selection, and ultimately population viability. $I_{M} / I_{F}$ is the opportunity for selection in males and females (respectively), $w$ is fitness and SST is sexually selected trait.

selection. The laws of thermodynamics pose constraints on biochemical processes inherent to metabolism and development, with cascading effects on organism physiology, morphology, phenology and behaviour. Temperature is a measure of the amount of kinetic energy in a system, and kinetic energy determines the rate of conformational changes in proteins (e.g. enzymes), the activation energy of reactants in biochemical reactions (Fields, 2001) and the fluidity of cell membranes, which in turn determines the transport of materials in and out of cells (Hazel \& Williams, 1990). In this way, kinetic effects ultimately impact performance of cell, organ and systemic (e.g. muscular, nervous, digestive) processes over a wide temporal scale that spans short-term effects (e. g. rapid metabolic changes measured in minutes/s), medium-term effects (i.e. within an ontogenetic phase, measured in hours/days) and long-term changes across different ontogenetic phases and - potentially - generations (reviewed in Abram et al., 2017). In the wild, temperature can vary significantly at all these time scales, setting the scene for its widespread effects on organism phenotypes. Precisely due to these effects, organisms have evolved behavioural and physiological responses to environmental temperature variation at all these time scales, arguably in a distinct way to other abiotic environmental variables (Abram et al., 2017). Ultimately, 
the scaling up of all these temperature effects can impact ecosystem-level processes such as population growth rates, trophic interactions or biomass production (Gillooly et al., 2001; Brown et al., 2004). Unsurprisingly, there is ample evidence that temperature strongly impacts all aspects of an animal's phenotype, including its physiology, morphology, phenology and behaviour (e.g. Hetem et al., 2014; Abram et al., 2017; Noble, Stenhouse, \& Schwanz, 2017b). For example, the metabolic theory of ecology poses that temperature is the main determinant of metabolic rate along with body size, which has itself partly evolved in response to environmental temperature (Gillooly et al., 2001; Brown et al., 2004).

Obviously, traits involved in sexual selection are no exception and thus temperature has the potential to modulate secondary sexual traits and how they co-vary with fitness, impacting both the intensity and the relative importance of sexual selection mechanisms. Conceptually, we suggest it is useful to distinguish between direct and indirect effects of temperature on sexual selection (Fig. 1). By direct effects we mean that temperature variation will translate into immediate changes in the selection and/or response to selection of secondary sexual traits, by affecting either the opportunity for selection, trait-fitness covariance or trait heritability. By indirect effects, we mean that temperature variation will affect the overall phenotypes, demography, trade-offs and/ or sex-specific reproductive costs/benefits of organisms in a way that can change sexual selection pressures (i.e. sexual selection optima). While this classification does not reflect a true dichotomy, and we actually discuss both types of effects together in Section III, we do believe it can be conceptually useful to think generally about the different processes involved. A similar distinction can be made regarding the type of temperature variation faced by organisms. More specifically, we believe it can be useful to distinguish between the effects of temperature variation within the range of temperatures under which organisms have adapted to reproduce in their recent evolutionary past versus maladaptive temperature variations (e.g. climate change) that will trigger stress responses (Fig. 1). Again, we note this distinction is not absolute, both because stress responses are adaptive in themselves and because the limits of 'natural' versus maladaptive temperatures is in most cases unclear. However, the type of evolutionary responses and underlying theory at play are likely to be qualitatively different in these two cases (Sections II.1 and II.2 below), and this distinction is useful in disentangling evolutionary responses to stressful stimuli that are not specific to temperature from responses that will be specific to temperature.

\section{(1) Direct effects of temperature on sexual selection}

First, maladaptive environmental variation, including temperature, can directly affect sexual selection. Fitness landscape theory predicts that the variability of secondary sexual traits under strong stabilising selection will be particularly affected by stressful temperature fluctuations, leading to pronounced genotype-by-environment interactions (Martinossi-Allibert, Arnqvist, \& Berger, 2017). Given that males are typically under stronger sexual selection than females (Janicke et al., 2016), this may lead to sex-specific environmental sensitivity and a concomitant change in the net opportunity for sexual selection (Martinossi-Allibert et al., 2017). In addition, Martinossi-Allibert et al. (2019a) recently showed that rapid environmental change can in principle result in less-effective good-genes sexual selection, at least in species where sexual selection takes place in smallto medium-size organisms (i.e. applicable to most animal species in the wild). This happens because stress increases selection on both sexes (by increasing the variance in fitness), but selection on females is 'harder' than on males so that the ratio of $I_{\mathrm{M}}$ (variance in male fitness) to $I_{\mathrm{F}}$ (variance in female fitness) decreases drastically (e.g. Martinossi-Allibert et al., 2018). Briefly, because female fitness depends on fecundity selection while male fitness depends on their ability to monopolise fertilizations within a mating patch, group size poses an upper limit for male (but not female) variance (Martinossi-Allibert et al., 2019a). By contrast, there is substantial theoretical and empirical work showing that genomic conflict between the sexes should be ameliorated in populations facing environments to which they are not adapted, hence increasing population adaptation (e.g. Long et al., 2012; Berger et al., 2014; Punzalan, Delcourt, \& Rundle, 2014). This happens, essentially, because natural selection under a maladaptive environment tends to align male and female interests. It is worth noting that the effects described above, however, are predicted in response to variations in any abiotic factor that places organisms in a maladaptive environment. In this sense, temperature may well be a particularly pervasive stressful abiotic factor, but the theoretical underpinnings of its effects are no different to other abiotic factors.

Maladaptive temperature changes have also been shown to have specific and widespread effects on essential features of reproduction (e.g. spermatogenesis) that may directly translate into changes in the opportunity for selection (e.g. Sales et al., 2018; Walsh et al., 2019). More importantly, inasmuch as the expression of many phenotypic traits is governed by temperature-dependent processes, both their mean and their variance can be affected by temperature variation regardless of whether such variation is maladaptive or not. Several studies have established links between temperature variation and changes in the levels of genetic variance (measured as additive genetic variances, heritability, or evolvability) of morphological or life-history traits (Bubliy \& Loeschcke, 2002; Sgro \& Hoffmann, 2002; Husby, Visser, \& Kruuk, 2011; Martinez-Padilla et al., 2017). Similarly, recent work suggests that, due to kinetic effects on protein functionality, elevated temperatures can cause a dramatic increase in the fitness effects of de novo mutations over a biologically relevant temperature range (D. Berger, J. Stanberg \& R. J. Walters, in preparation). Temperature variation can hence affect the variance in the reproductive success of males and females $\left(I_{\mathrm{M}} / I_{\mathrm{F}}\right)$, and with it the opportunity for selection. In short, temperature variation within both 
adaptive and maladaptive ranges can directly modulate the variance in reproductive traits, in fitness (i.e. opportunity for selection), and the co-variance between the two, thus directly affecting sexual selection (Fig. 1).

\section{(2) Indirect effects of temperature on sexual selection}

There are numerous ways in which temperature variation, both within and outside the range of temperatures organisms have adapted to, can indirectly affect sexual selection. First and foremost, there are several pathways by which temperature can affect key parameters of the mating system (i.e. the ecology of sexual selection) that will end up modulating the opportunity for selection (e.g. sex-specific potential reproductive rates, operational sex ratios, density, etc.). Sex-specific reproductive costs and benefits are, in many cases, largely dependent on the environment (e.g. costs of investment in offspring, sex-specific mortality linked to reproduction, costs of parental care, etc.), and are also amenable to be modulated by temperature, hence potentially impacting sex-specific selection pressures and the opportunity for sexual selection (e.g. Grazer \& Martin, 2012). The same rationale holds for trade-offs (e.g. those depending on physiological constraints) and population demography (e.g. population growth rate mediated by nutrient availability), which we also discuss in Section III. Finally, indirect effects will also include the influence of temperature on other abiotic factors that can directly (e.g. oxygen concentration in air/water) or indirectly (e.g. humidity, water turbidity etc.) affect animal phenotypes, and ultimately shape sexual selection processes.

\section{SPEGIFIC PATHWAYS FOR TEMPERATURE EFFEGTS ON SEXUAL SELEGTION}

\section{(1) Temperature effects on secondary sexual traits and associated preferences}

\section{(a) Behaviour, physiology and life-history traits related to sexual selection}

Temperature has been shown to drive changes in many facets of reproductive behaviour that can determine sexual selection, including underlying physiological mechanisms. For example, temperature is a key determinant of metabolism and activity levels in most species of animals (Kearney et al., 2010; Gunderson \& Leal, 2015), which can directly affect mate searching, the number of male-male and malefemale interactions, and general patterns of male and female spatio-temporal distribution. In the ambush bug (Phymata americana), sexual dimorphism in colour has been shaped by sexual selection on thermoregulatory performance, whereby dark males have higher mate-searching success at cool ambient temperatures (Punzalan, Rodd, \& Rowe, 2008). Similarly, temperature can modulate male-male competition intensity (e.g. aggressiveness; Kvarnemo, 1998), courtship rates, mating latency and duration (Jiao et al., 2009), female choice (Conrad, Stocker, \& Ayasse, 2017), re-mating rates (Katsuki \& Miyatake, 2009), and female fecundity (Nunney \& Cheung, 1997). There are also studies showing that temperature affects sexual signals and/or sexual signalling behaviour or perception (Linn, Campbell, \& Roelofs, 1988; Llusia et al., 2013; Sentis et al., 2015; Conrad et al., 2017; Groot \& Zizzari, 2019), with potential impacts on mate choice and intra-sexual competition. Actually, any effect of temperature on the phenotypic mean and variance of sexually selected characters is likely to influence selection on a secondary sexual trait (i.e. the covariance between trait value and relative fitness). Given that the expression of many traits (including secondary sexual traits) can be dependent on temperature (West \& Packer, 2002; House et al., 2013; Reinhardt, Dobler, \& Abbott, 2015), its significance to understand mate preferences and sexual selection at large is evident.

Post-copulatory processes have also been reported to be under the influence of temperature. It is well known that the sperm phenotype is in many species contingent on temperature (Reinhardt et al., 2015; Sales et al., 2018; Walsh et al., 2019). Most notably, sperm competition ability (i.e. in terms of both sperm offence and defence) is affected through the amount and quality of sperm transferred (Katsuki \& Miyatake, 2009; Lieshout, Tomkins, \& Simmons, 2013; Vasudeva, Deeming, \& Eady, 2014). For example, a recent study in the Mediterranean field cricket (Grillus bimaculatus) showed that $4^{\circ} \mathrm{C}$ temperature differences (within the natural range of variation of the study population in the wild) significantly affected sperm production and quality. Males had higher sperm production and quality when they were exposed to hotter temperatures throughout development, but the opposite was true if they were exposed to hotter temperatures as adults (Gasparini et al., 2018). In addition, temperature also impacted offspring fitness via effects on male sperm (i.e. non-adaptive paternal effects). These results show that temperature effects on sperm traits and overall competitiveness may depend on the temporal scale of temperature fluctuations with respect to ontogeny, highlighting the potential for trans-generational effects. Sperm competitiveness determines siring success, which together with mating success is the main component of male reproductive success in polyandrous species. Critically, then, the action of temperature on sperm competitiveness has the potential to directly affect the opportunity for sexual selection, either through its effects on male variance in post-copulatory reproductive success or on the covariance between the pre-mating and post-mating episodes of sexual selection (Evans \& GarciaGonzalez, 2016).

Finally, temperature can exert significant changes in lifehistory traits across different species and populations (Jensen et al., 2008; Isaac, 2009), some of which are sex-specific (Rogell et al., 2014). Many of these changes (e.g. in lifespan, the onset of reproduction, survival, age or size at maturity) have great potential to affect parameters modulating intraor inter-sexual selection, such as the operational sex ratio 
(OSR), the potential reproductive rate or the environmental potential for polygyny/polyandry.

\section{(b) Body size and sexual size dimorphism}

Body size, a primary determinant of both inter- and intrasexual competition, is under the influence of environmental temperature through both plastic and evolutionary responses (Fox, Stillwell, \& Moya-Larano, 2007; Lindmark et al., 2018). For example, temperature has been shown to reduce sexual dimorphism in some insects by modifying emergence times and developmental rates (De Block \& Stoks, 2003; Ketola et al., 2012). This is predicted to decrease the capacity of males to monopolise females, and with it the opportunity for selection (Fox et al., 2007; Vanpa et al., 2008). In the seed beetle Stator limbatus temperature can affect scramble competition, whereby smaller males are more successful at finding mates than large males when at cool temperatures (MoyaLaraño, El-Sayyid, \& Fox, 2007). Similarly, temperature is one of the main environmental factors underlying phenotypic plasticity in body size, and the sexes commonly show marked difference in their degree of phenotypic plasticity to body size (Stillwell et al., 2010). For example, males of the seed beetle Callosobruchus maculatus exhibit greater plasticity in body size than females in response to temperature manipulations (Stillwell \& Fox, 2007), and existing evidence shows that, in insects, male body size varies more with latitude and altitude than does female body size (Blackenhorn et al., 2006). Some of these differences in sexual size dimorphism may be explained by the 'condition-dependence hypothesis', which predicts that traits under stronger directional selection will be more condition dependent, and hence more responsive to environmental cues (Bonduriansky, 2007). It would be interesting to explore whether the larger sex is generally more affected by stressful temperature changes than the smaller sex, and how this may affect sexual selection.

\section{(c) Mate choice preferences}

We have long known that temperature can affect mate choice preferences in both vertebrates and invertebrates. For example, classic studies by Walker (1957), in crickets, and by Gerhardt (1978), in anurans, described thermal coupling, whereby female preferences shift to track temperaturedependent changes in male sexual signals. Thermal coupling may reflect adaptive phenotypic plasticity or non-functional physiological responses to temperature (Ritchie et al., 2001; Greenfield \& Medlock, 2007), but at least in some cases it will act to buffer mate choice against disruption by temperature fluctuations (Beckers \& Schul, 2008). In other cases, however, temperature effects on preferences can disrupt mate choice processes. For example, in the American green tree frog (Hyla cinerea) temperature effects on female preferences are not matched by changes in male signals, potentially hampering species recognition at low temperatures (Gerhardt \& Mudry, 1980). Similarly, in the pipefish Sygnathus abaster warm temperatures seem to affect female preferences towards males (Silva et al., 2007). More generally, temperature may also indirectly affect female preferences via its effects on body condition. In some species, females in good condition have been shown to exert stronger preferences and/or invest more in mate assessment (Cotton, Small, \& Pomiankowski, 2006; Hebets, Wesson, \& Shamble, 2008).

\section{(2) Temperature effects on mating systems}

The strength and form of sexual selection ultimately depend on the mating system, and hence on the 'ecology of sexual selection' (Emlen \& Oring, 1977; Schuster \& Wade, 2003). First, there are multiple ways in which temperature can affect the environmental potential for polygyny/polyandry, that is the potential for the environment (e.g. clumped resources) to allow for the monopolisation of multiple mates (Emlen \& Oring, 1977). For example, by prolonging/shortening the reproductive season (Sheriff et al., 2011), temperature shifts may make female reproduction more or less synchronous and/or clump/spread out the breeding population in time. This may increase/decrease male opportunities to monopolise females and, ultimately, the environmental potential for polygyny/polyandry (Olsson et al., 2011). In the barn swallow (Hirundo rustica), warming temperatures have been reported to increase protandry, and this has been associated with an increase in the size of a secondary sexual character, which is suggestive of stronger sexual selection (Moller, 2004). Female reproductive diapause (i.e. period of reproductive arrestment in response to adverse environmental conditions, such as low temperatures in winter) is also at least partially controlled by temperature in many insect species. By contrast, males usually either lack reproductive diapause or it is less intense than in females (Pener, 1992). As such, temperature effects on the onset/outset of female reproductive diapause can, in theory, affect the synchrony of female receptivity within the reproductive season, with potential consequences for levels of polygyny and polygamy.

Second, several studies have shown that temperature can drastically modulate the potential reproductive rate (PRR) of males and females in a sex-specific manner (Kvarnemo, 1994). For example, environmental temperature has frequently been found to affect the availability of nutritional resources during reproduction (Vatka, Orell, \& Rytkönen, 2011), which is generally expected to affect female PRR more than male PRR because egg production is particularly dependent on food intake in many animals (Warner, Lovern, \& Shine, 2007). Much in the same way, temperature shifts are likely to affect oviposition site availability in many species (e.g. Fogleman, 1979; Berger, Walters, \& Gotthard, 2008), which could also differentially affect the PRR of females. On the other hand, high temperature may differentially increase male (versus female) PRR if male reproductive rates are particularly dependent on activity levels, as is frequently the case in species with resource-defence polygynous systems. Temperature also drastically influences incubation time, particularly in species where egg development 
depends almost exclusively on environmental temperature (most ectotherms), thus greatly determining the PRR of the sex in charge of incubation and brood care (Kokko \& Jennions, 2008; Kokko, Klug, \& Jennions, 2012). This is the case in sand gobies (Pomatoschistus minutus), where males build a nest and care for the eggs until hatching. Increased temperature accelerates egg developmental rates and ultimately male PRR, as they can be alleviated from egg guarding sooner (Kvarnemo, 1994).

Sex-specific temperature effects on polygyny/polyandry levels and PRR are ultimately expected to modulate the OSR by modulating how and when males and females enter and exit the mating pool, and hence the strength of sexual selection (Kvarnemo, 1996; Schuster \& Wade, 2003; Kokko et al., 2012). Temperature can also directly affect the OSR in species with temperature-dependent sex determination (Grayson et al., 2014; Cunningham, While, \& Wapstra, 2017), or if the sexes have different reproductive operational temperature ranges. The latter will be particularly likely in species with strong sexual size dimorphism. For example, in species where females are larger than males, females may exhibit a greater acclimation capacity in response to temperature fluctuations and extremes (Rohr et al., 2018) and, hence, be reproductively active over a wider range of temperatures (Stone, 1994). The implication is that the OSR will be progressively more female-biased as temperatures approach the thresholds of the male reproductive operational thermal range.

Finally, population density can influence mating systems, and hence sexual selection processes, in many taxa. Population density (and population dynamics at large) is frequently under the influence of temperature (Gamelon et al., 2017), and can strongly affect mating skew or mate encounter rates, for example, with cascading effects on mate choice, mate guarding, re-mating rates or female resistance (Kokko \& Rankin, 2006). Through its effects on population density, temperature could thus also influence sexual selection (Fig. 1).

\section{(3) Temperature effects on sex-specific costs/ benefits of reproduction}

Changes in environmental temperatures can alter the costs/ benefits of reproduction in a sex-specific way (e.g. costs of investment in offspring, sex-specific mortality linked to reproduction, costs of parental care, offspring survival, etc.), impacting sex-specific selection pressures and the opportunity for sexual selection. For example, Grazer \& Martin (2012) showed that the survival costs of reproduction for females of the flour beetle Tribolium castaneum decrease at higher temperatures. Studies looking at how temperature may affect sex-specific reproductive costs and benefits are still very scarce and focus on the short-term plastic consequences of thermal stress, yet provide good preliminary evidence that such effects are not only possible, but may be theoretically expected (Martinossi-Allibert et al., 2017). More generally, the relative importance of intra- and inter-sexual selection can also vary with environmental conditions (Miller \& Svensson, 2014). For example, in collared flycatchers (Ficedula albicollis) mate choice has a heritable component, and selection on mate choice varies annually according to climatic conditions: females choosing highly ornamented males have increased reproductive success in dry breeding seasons but low relative reproductive success in wet breeding seasons (Robinson et al., 2012). To our knowledge, however, there is no evidence thus far of similar effects mediated by temperature.

\section{(4) Temperature effects on constraints and trade-offs}

Temperature may also modulate sexual selection through its effects on physiological trade-offs. For example, environmental temperatures can affect pathogen abundance and virulence, as well as host susceptibility and immune responses (Elliot, Blanford, \& Thomas, 2002). Several studies have also shown that immunity is related to body condition, and that it trades off with reproductive effort and primary and secondary sexual traits (Simmons \& Roberts, 2005; Cotter et al., 2010; Mills et al., 2010). Therefore, studying the interplay between thermal ecology and immune ecology, and their combined effects on sexual selection, may inform on other avenues thorough which temperature can affect sexual selection. Similarly, temperature can shape the costs and benefits of secondary sexual traits, for example of visual signals that may also play a role in thermoregulation. This seems to be the case for the sexually selected male wing colouration in the dragonfly Pachydiplax longipennis. In this species, greater wing colouration improves flight performance under cool conditions (leading to greater territory acquisition), but dramatically reduces it under warm conditions, which seems to constrain the evolution of sexual colouration in the hottest portions of the species' range (Moore et al., 2019). As stated above, some studies have also established links between temperature variation and changes in the levels of genetic variance (measured as additive genetic variances, heritability, or evolvability) and in morphological or life-history traits (Bubliy \& Loeschcke, 2002; Sgro \& Hoffmann, 2002; Husby et al., 2011; Martinez-Padilla et al., 2017). These results show that the evolutionary potential of populations to adapt to changing environments is constrained by genetic architectures that can be temperature dependent. For instance, Martinez-Padilla et al. (2017) used data from 20 European wild bird populations belonging to 12 species, and found that the evolutionary potential of traits relating to body size and body mass (relevant to sexual selection in general) were associated with environmental favourability, which was greatly influenced by temperature.

\section{(5) Temperature effects on population dynamics/ demographics}

Temperature can affect sexual selection through its impact on population demography/dynamics (Gavrilets, 2000; 
Gay et al., 2010). Temperature variation can underlie changes in population growth (e.g. through the availability of nutrients; Clark et al., 2003), pose limits to population size (e.g. modify population carrying capacity; Newman, 2003), determine the spatial-temporal distribution of populations and individuals (e.g. driving population subdivision and consequently altering population sizes and the probabilities of encountering the opposite sex; Yasui \& Garcia-Gonzalez, 2016), and affect population viscosity (i.e. limit dispersal), mating patch size and sexual networks (McDonald et al., 2013; Pizzari, Biernaskie, \& Carazo, 2015; McDonald \& Pizzari, 2018; McDonald et al., 2019). As such, temperature may modulate sexual selection at a large taxonomic scale. Importantly, while some of the temperature effects on population dynamics are predicted to be temperature-specific, via the scaling of integrated effects (Gillooly et al., 2001; Brown et al., 2004; Abram et al., 2017), others will simply be due to correlated effects via other abiotic factors.

\section{(6) Abiotic factors correlated with temperature}

Some of the effects described above may be at least partly driven in nature by abiotic factors that are correlated with temperature, and not necessarily by temperature per se, such as temperature effects through the availability of nutrients (Clark et al., 2003). For example, increases in environmental temperature may facilitate eutrophication and consequently lead to elevated water turbidity (Paerl \& Paul, 2012), with obvious consequences for the action of sexual selection in aquatic animals in which mate choice is based on visual signals. Human activities leading to higher turbidity have been shown to threaten the biological diversity of one of the most notable examples of explosive evolution known, the highly diverse species flocks of cichlid fish from the Great Lakes of Africa. In these fish, water turbidity is known to interfere with mate choice and to relax sexual selection (Seehausen, Alphen, \& Witte, 1997; Maan \& Seehausen, 2011), and similar findings have been reported in other systems (Engstrom \& Candolin, 2007; Candolin, Tukiainen, \& Bertell, 2016). By contrast, in the broad-nosed pipefish (Syngnathus typhle; a species with male pregnancy), turbidity strengthens sexual selection (Sundin et al., 2017). Humidity is an abiotic factor that is also closely linked to temperature, and there is some evidence that it could also affect sexual selection. In the common lizard (Zootoca vivipara), for example, post-natal humidity differentially affects female versus male growth, thereby influencing adult sexual size dimorphism and, potentially, sexual selection (Le Galliard et al., 2006). Nonetheless, due to the widespread thermodynamic constraints on enzymatic activity, the resulting physiological, morphological, behavioural and life-history traits of organisms are inherently temperature dependent (Brown et al., 2004; Clarke, 2004). Hence, temperature is likely to be generally more determinant for sexual selection processes than other abiotic factors.

\section{TEMPERATURE AND SEXUAL GONFLICT}

A particularly direct link between sexual selection and population viability emerges due to the consequences of sexual conflict. Strong sexual selection frequently leads to sexual conflict, where male and female evolutionary interests do not coincide. While classic theory of sexual selection often assumed that male/female coevolution is largely mutualistic, an increasing appreciation of sexual conflict has led to the realisation that genes that confer a reproductive advantage to males may have the opposite effect in females, and vice versa. According to the genetic underpinnings of the traits under sexual selection, sexual conflict can take two qualitatively distinct forms: inter-locus or intra-locus sexual conflict. Inter-locus sexual conflict (IRSC) occurs in relation to traits governed by genes that are at different loci in males and females, and where expression benefits one sex at the cost of the other. IRSC frequently gives rise to an antagonistic process of inter-sexual coevolution (Arnqvist \& Rowe, 2005), particularly in polygamous species where males and females often show different optima for mating frequencies and reproductive schedules (Chapman et al., 1995; Rice, 1996; Holland \& Rice, 1999; Arnqvist \& Rowe, 2005). Sexually antagonistic coevolution has received much attention in recent years (Rice, 1996; Holland \& Rice, 1999; Wigby \& Chapman, 2004), and is currently recognised as one of the key evolutionary processes shaping male and female adaptations and life-history traits (Bonduriansky et al., 2008), but also population viability and diversification. Intra-locus sexual conflict (IASC) arises when there is sex-specific selection on a trait expressed in both sexes and the shared genetic architecture underlying the expression of the trait impedes optimal expression levels in each sex (Arnqvist \& Rowe, 2005). The theoretical basis of IASC was developed long ago (Lande, 1980; Rice, 1984) and, although its effects have proved to be more subtle than IRSC, it is receiving increasing empirical attention (Bonduriansky \& Chenoweth, 2009).

Sexual conflict can, via IRSG and IASC, act both as an engine of biodiversity and to decrease population viability. On the one hand, sexually antagonistic coevolution can function as an engine of biodiversity, both by leading to and/or reinforcing reproductive isolation and speciation (Parker \& Partridge, 1998; Rice, 1998) and by promoting increased intra-specific genetic variation without speciation (Gavrilets, 2014). On the other hand, sexually antagonistic selection can lead to adaptations in one sex (most frequently males) that harm members of the other sex (most frequently females; Pitnick \& Garcia-Gonzalez, 2002). As a matter of fact, male adaptations that cause harm to females, and female adaptations to resist such harm, are indeed paradigmatic examples of IRSC (Arnqvist \& Rowe, 2005). Male harm to females generally leads to a decrease in population productivity [i.e. by depressing net female productivity (Holland \& Rice, 1999; Arnqvist \& Tuda, 2010; Berger et al., 2016)] that can facilitate population extinction (Le Galliard et al., 2005). Furthermore, sexual conflict can also decrease male and female 
fitness by displacing the sexes from their respective evolutionary optima (normally referred to as 'gender load' but hereafter referred to as 'sex load'; Rice \& Chippindale, 2002), normally via IASC. Ultimately, whether sexual conflict fosters biodiversity or reduces population productivity and facilitates extinction will depend, among other things, on population size (Gay et al., 2010), the potential for sex load (Berger et al., 2016), and the degree and form of associated male harm adaptations and female counter-adaptations (Arnqvist \& Rowe, 2005). In addition, sexual conflict can feed back to affect the opportunity, form and/or intensity of sexual selection. For example, avoiding male harassment (a common source of harm to females) in crickets leads to a larger opportunity for (and stronger) sexual selection (Hall et al., 2008). To summarise, there is now ample theoretical and empirical evidence that sexual conflict is a fundamental engine of biodiversity, a driving force of male and female adaptations and life histories, and a keystone determinant of population viability and extinction risk.

Despite the impressive advances in the field of sexual conflict, we are still far from being able to explain the overwhelming diversity of related adaptations or their net impact on population viability. The apparently arbitrary nature of the coevolutionary trajectories that often result from strong sexual conflict has been sometimes interpreted to mean that ecology occupies a rear seat in such processes, or is altogether irrelevant (Coyne \& Orr, 2004; Arbuthnott et al., 2014). This, however, seems highly unlikely given that sexual conflict depends on the intensity of male-male competition, and sexual selection is profoundly affected by ecological factors. In fact, there is now good evidence to show that the opportunity for sexual conflict does depend on the ecological context (Arbuthnott et al., 2014; Perry et al., 2017; De Lisle et al., 2018; Gomez-Llano, Bensch, \& Svensson, 2018; Perry \& Rowe, 2018), including maladaptive environmental changes (Connallon \& Clark, 2014) and environmental fluctuation per se (Connallon \& Hall, 2018).

Temperature can in principle modulate both adaptations for sexual conflict (e.g. by affecting the expression of adaptations leading to male harm via behavioural plasticity) and sexual conflict itself, through its effects on the degree to which male and female interests overlap. A few studies have shown that stressful temperature environments (and stressful environments at large) can relax sexual conflict, because in a maladaptive environment male and female interests may tend to overlap more due to strong concordant selection in new environmental conditions (Long et al., 2012; Berger et al., 2014; Connallon \& Hall, 2018, but see Delcourt, Blows, \& Rundle, 2009; Punzalan et al., 2014; Connallon \& Hall, 2016; Holman \& Jacomb, 2017; Martinossi-Allibert et al., 2018). However, there is scarcely any information on whether non-extreme temperature fluctuations at an ecologically relevant temporal (i.e. circadian, seasonal, or inter-seasonal) and/or spatial (i.e. micro- and macrogeographic) scale modulate sexual conflict.

\section{(1) Temperature effects on inter-locus sexual conflict}

Temperature can be expected to modulate IRSG in two ways. First, by constraining or conditioning the expression of male/female traits evolved via IRSC. For example, García-Roa et al. (2019) manipulated sexual conflict levels in Drosophila melanogaster and showed that resulting male harm to females decreased sharply in both colder $\left(21^{\circ} \mathrm{C}\right)$ and hotter $\left(29^{\circ} \mathrm{C}\right)$ social environments than at the average temperature to which the population was adapted $\left(25^{\circ} \mathrm{C}\right)$. In this species, therefore, temperature shifts are likely modulators of male harm mechanisms [e.g. production of sperm and/or toxic components in the ejaculate (Chapman et al., 1995; Perry, Sirot, \& Wigby, 2013)], which is perhaps to be expected whenever male harm adaptations cannot be optimally expressed across the whole range of temperatures at which reproduction ensues. D. melanogaster exhibits both pre-copulatory (i.e. sexual harassment) and post-copulatory (i.e. toxic ejaculates) mechanisms of male harm and, interestingly, preliminary evidence suggests these are affected differently by warm versus cold temperatures (García-Roa et al., 2019). Investment in pre- versus post-copulatory male-male competition traits/mechanisms can be traded-off via resource allocation (e.g. Simmons \& Emlen, 2006), and male ejaculates have been shown to manipulate female mating frequency and affect the balance between pre-copulatory and post-copulatory sexual selection in D. melanogaster (Morimoto et al., 2019). Hence, such temperature effects are likely to modulate both the total opportunity for sexual selection and the integration between pre- and post-mating processes (Evans \& Garcia-Gonzalez, 2016). Recent work on seed beetles (Callosobruchus maculatus) has also reported evidence that a stressful increase in temperature can reduce IRSC in populations evolved under polygamous/monogamous conditions and then tested under different levels of sexual conflict (single pairs versus groups of 10 beetles); interestingly, this is not the case in populations with male-limited evolution (MartinossiAllibert et al., 2019b).

Second, variation in temperature, such as consistent spatial inter-population differences or long-term intra-population fluctuations, can vary the degree to which male and female reproductive interests diverge. This type of effect may modulate the intensity and/or direction of sexually antagonistic coevolution. For example, Perry et al. (2017) showed that different ecological parameters, among them temperature, contributed to explaining inter-population differences in a sexually antagonistic arms race in natural populations of water striders (Gerris incognitus); likely due to inter-population differences in ecological forces acting on mating system variation and ensuing sexual conflict (Perry \& Rowe, 2018).

\section{(2) Temperature effects on intra-locus sexual conflict}

As in the case of IRSC, spatio-temporal variation in temperature can modulate IASC by changing the degree to which 
male and female interests overlap. IASG is generally expected to decrease in novel environments, for example due to concordant natural selection of previously neutral alleles in both sexes (Long et al., 2012). In accordance with theory, Berger et al. (2014) showed that sex load via intralocus sexual conflict is reduced in a natural population of seed beetles (Callosobruchus maculatus) subject to a stressful thermal environment (but see Martinossi-Allibert et al., 2019b). To conclude, there is now theoretical and empirical evidence to show that temperature does indeed have the potential to modulate both IASC and IRSC. Interestingly, data so far seem to suggest that the negative impact of sexual conflict on population viability, due both to sex load and female harm, may be ameliorated when populations face temperature changes. We suggest that exploring this idea should be a priority in the near future, not only because it will further our understanding of sexual conflict but also because, in species with high sexual conflict, this type of effect can ultimately increase the ability of populations to avoid extinction in the face of persistent anthropogenic temperature changes (e.g. global warming).

\section{TEMPERATURE, SEXUAL SELEGTION AND RAPID ENVIRONMENTAL GHANGE}

From an eco-evolutionary point of view, rapid environmental change results in a mismatch between an organism's optimal and current environment, potentially leading to population decline and extinction. Whether a population is able to withstand such environmental change and avoid extinction over the long term will depend essentially on whether it is capable of adapting quickly enough to track these changes (Parmesan, 2006; Hoffmann \& Sgro, 2011; Kingsolver \& Buckley, 2017; Martinez-Padilla et al., 2017). Most studies that try to predict the consequences of rapid environmental change for natural populations focus on studying the direct effects of temperature shifts on phenotypic traits that respond plastically to temperature, and then examine how these changes affect population viability, and the potential for subsequent evolutionary rescue. Above we have reviewed how these effects can shape sexual selection through a variety of pathways (Fig. 1). In doing so, the initial impact of a sustained temperature shift can feed back to influence a wide diversity of phenotypic traits that are not directly affected by temperature. Furthermore, as mentioned above sexual selection has great potential to influence the fate of populations/species (Cally et al., 2019), especially those facing directional environmental changes such as for example those imposed by global warming (Candolin \& Heuschele, 2008). In particular, recent evidence has shown that strong sexual selection can help buffer against warming temperatures, with experimental populations facing rising temperatures having higher fecundity and offspring survival when under a strong sexual selection regime (Plesnar-Bielak et al., 2012; Parrett \& Knell, 2018). This means that any effects of temperature on sexual selection are likely to feed back and impact a wide range of phenotypic traits linked with population viability and extinction via genic capture of sexually selected traits. In addition, current projections predict global warming to result not only in an increase in mean and modal temperatures, but also in temperature fluctuations at any given spatial scale (IPCC, 2014). This makes it all the more important to understand how such fluctuations may impact sexual selection via both short-term plastic changes and long-term evolutionary responses.

\section{PROCESSES INVOLVED IN EFFEGTS OF TEMPERATURE ON SEXUAL SELEGTION}

An overarching question to the links we have described so far is what type of responses (adaptive and non-adaptive) may result from temperature shifts in the environment. Adaptive population-level responses in the face of environmental change can ensue through both natural selection (including sexual selection), by exploiting existing genetic variation, and through phenotypic plasticity, by exploiting the ability of individuals to adjust their phenotype to the environment and/or by revealing cryptic genetic variation that can later be the target of selection, via genetic assimilation (West-Eberhard, 2003; Snell-Rood et al., 2010; Gilbert, Bosch, \& LedonRettig, 2015). For example, high developmental temperatures have been shown to reveal cryptic genetic variation in female sperm compartments of the yellow dung fly (Scathopaga stercoraria), which play a key role in cryptic female choice in this species (Berger et al., 2011). Phenotypic plasticity (whether adaptive or maladaptive) is likely to be of particular importance in understanding temperature-mediated effects on sexual selection for the obvious reason that development is critically affected by environmental temperature in most species, and particularly so in ectotherms. Accordingly, meta-analyses have identified strong long-lasting effects of developmental temperature on suites of traits, such as growth rate, physiology, performance and morphology (Seebacher, White, \& Franklin, 2014; Noble et al., 2017b). Behavioural plasticity, including paternal effects, might also be very important because it is a way in which parents can buffer the developmental temperature of their offspring, mitigating the consequences of environmental temperature shifts (Huey, Hertz, \& Sinervo, 2003; Du \& Shine, 2015).

As in any selective process, evolutionary responses to changes in temperature will depend on the amount of additive genetic variation underlying the trait or traits affected. Interestingly, temperature fluctuations may actually play a role in the maintenance of genetic variation underlying sexually selected traits and mate preferences through genotype-by (temperature-determined) environment interactions. Evidence for such role of temperature variation has been found across study systems (Jia, Greenfield, \& Collins, 2000; Narraway et al., 2010; Hunt \& Hosken, 2014; Miller \& Svensson, 2014), and plastic responses to novel environments 
more generally tend to align with underlying additive genetic variation in traits (Noble, Radersma, \& Uller, 2019).

Finally, temperature is also likely to impact sexual selection through inter-generational and trans-generational effects. First, because temperature is frequently a cue for many other sources of environmental variation (e.g. food availability, onset of reproductive/breeding period, etc.). Second, because temperature affects a host of physiological mechanisms with consequences that may spill over to subsequent generations via paternal effects or the transmission of epigenetic marks. Paternal germline epigenetic changes that are environmentally triggered are increasingly recognised as modulators of sperm function (Stuppia et al., 2015; Jenkins et al., 2017) but also, remarkably, as sources of variance in the offspring phenotype (Miller, Brinkworth, \& Iles, 2010; Stuppia et al., 2015; Jenkins et al., 2017; Wang, Liu, \& Sun, 2017; Donkin \& Barres, 2018; Evans et al., 2019). In the nematode Caenorhabditis elegans, for instance, temperature variation induces multigenerational inheritance of gene expression through both oocytes and sperm (Klosin et al., 2017). Demonstrating such long-lasting epigenetic memory of parental temperature experiences, and at the same time unravelling the underlying mechanisms, is challenging and has been seldom achieved (Klosin et al., 2017). Nonetheless, there are reasons to suspect that temperatureinduced transmission of epigenetic marks affecting sperm and offspring phenotypes may be common (Evans et al., 2019). In most systems, we ignore whether cross-generational effects driven by paternal environment are driven by epigenetic mechanisms or mediated by other factors [e.g. direct or female-moderated paternal effects arising from variation in the non-sperm fraction of the ejaculate (Garcia-Gonzalez \& Simmons, 2007; Gasparini et al., 2018)]. However, any inter-generational or trans-generational effect has the capacity to significantly alter the economics of sexual interactions (Dowling, Williams, \& Garcia-Gonzalez, 2014; Zajitschek et al., 2018), leading to unknown but presumably significant effects on sexual selection. We anticipate that investigations focusing on how temperature-driven maternal and paternal effects impact sexual selection will yield important insights.

\section{META-ANALYSIS: EXPERIMENTAL EVIDENCE THAT TEMPERATURE IMPAGTS SEXUAL SELEGTION}

To test whether available data support the idea that temperature can significantly modulate sexual selection, we conducted a systematic review and meta-analysis of the existing literature focusing on studies that experimentally manipulated temperature and measured its impact on either: $(i)$ mating or reproductive success of males and/or females, or (ii) its effect on traits known to be under sexual selection. While excellent observational studies exist, given that temperature can be correlated with a host of other environmental changes, we avoided including correlative studies in our meta-analysis. Our focus in this meta-analysis is to explore temperature effects per se, beyond any effects that temperature may have due to subjecting individuals/populations to a new environment to which they are maladapted. Environmental stress can modulate the strength of sexual selection in a variety of ways (Arbuthnott \& Whitlock, 2018), for example increasing sexual selection if the variability in fitness is inflated when populations are pushed off their fitness peak (Martinossi-Allibert et al., 2017, 2018). As such, drastic temperature changes can modulate sexual selection not due to specific effects of temperature but by imposing a stressful environment, much in the same way as a pollutant or a sharp change in another abiotic factor would. To avoid conflating this type of effects, here we also explicitly avoided studies implementing heat/cold shock treatments and also assessed the potential influence of using extreme temperature treatments (Section VII.3).

It is also important to note that there are no clear theoretical expectations regarding the directionality of temperature effects on sexual selection processes. As laid out above, increases/decreases in temperature are not necessarily expected to impact sexual selection parameters in the same direction across different species. Some biological processes will tend to exhibit monotonic relationships in temperature that are relevant to selection. For example, given that temperature constrains certain fundamental biochemical properties such enzymic reactions, it has recently been proposed that mutations will have increasing fitness effects, and hence lead to stronger selection, with increasing temperatures (D. Berger, J. Stanberg \& R. J. Walters, in preparation). However, the net relationship between temperature and sexual selection across taxa is likely to rest largely on the physiology, morphology, behaviour and mating system of each species. Thus, our main aim was not so much to explore the directionality of the relationship between temperature and sexual selection, but to test the more general prediction that temperature has the potential to affect sexual selection in different species, irrespective of direction.

\section{(1) Literature search and data collection}

We conducted a systematic review and meta-analysis of the existing literature following the PRISMA protocol (Liberati et al., 2009) as closely as possible. More specifically, we looked for studies that experimentally manipulated temperature and measured its impact on either: $(\imath)$ mating or reproductive success of males and/or females, or (ii) traits known to be under sexual selection. We only extracted phenotypic trait values when it was clear from the reported paper, or the raw data, that the trait directly impacted reproductive success. If traits had a tenuous link with reproductive success they were not included. We conducted a first literature search on 11/09/ 18 using the Scopus, PubMed and Web of Science (WoS) databases with the search terms "sexual selection" AND "selecti* intensity" AND "temperature" or "sexual selection" AND "selecti* strength" AND "temperature" for animal taxa. Overall, very few papers were found with these search strings 
(21 total: Scopus $=5$, PubMed $=11$ and $\mathrm{WoS}=5$ ). After removing duplicates only 15 papers were relevant and two more were added through forward and backward searches of citations and references in the 15 papers. Given the small number of hits, we conducted a second search on 17/09/ 18 across the same databases (i.e. Scopus, PubMed and WoS), using a more general search query: "sexual selection" AND "fitness" AND "temperature" OR "mating success" AND "fitness" AND "temperature" OR "reproductive success" AND "fitness" AND "temperature". This search string was able to capture a broader set of studies for screening. In total, we found 747 studies (Scopus $=291 ;$ PubMed $=98 ; \mathrm{WoS}=358$ ) and after removing 249 duplicates, we were left with 498 unique studies for more detailed screening. Based on the title and abstract we excluded studies that were not on animals $(\mathcal{N}=38)$, had no measure of sexual selection or traits under sexual selection $(\mathcal{N}=354)$, did not involve a temperature manipulation $(\mathcal{N}=145)$, and where the effects of temperature could not be isolated because they were confounded by other abiotic or biotic variables $(\mathcal{N}=46)$. We also excluded $\mathcal{N}=12$ review and theoretical model papers. Note that many studies met more than one of the above criteria, and after this search we were left with a total of 61 papers across both searches as being potentially relevant. We carefully screened these papers to identify articles that met all our above inclusion criteria, and at this stage we also excluded all papers reporting heat/cold shock treatments), which left us with a final set of 19 studies (see online Supporting information, Table S1).

We extracted mean fitness or trait value from each temperature treatment along with the standard deviation and sample size for each group from tables and figures using the $\mathrm{R}$ package metaDigitise to extract from figures (Pick, Nakagawa, \& Noble, 2018). Experimental designs were highly variable across studies and there were designs that exhibited some level of non-independence in replicate measurements within temperature treatments (e.g. measurements of replicate individuals from isofemale lines). Given that this can affect the sampling variance of the effect size we used conservative sample sizes (i.e. the number of independent lines, or number of mating cages; Noble et al., 2017a). However, when raw data were available, and could be clearly interpreted, we calculated an intraclass correlation coefficient for the clusters (e.g. lines) and computed an 'effective sample size' for the treatment and used this for calculating the sampling variance (Noble et al., 2017a). Fitness was often reported on a proportion scale (e.g. the average proportion of mating's/offspring sired). While these are not normally distributed, they were often treated as so in the paper, and given that we required ratio-scale data for our effect sizes (see Section VII.2) we assumed that these were approximately normally distributed in accordance with the study. Nonetheless, we conducted a sensitivity analysis to determine if effect sizes calculated with proportion data were different than non-proportion data and included this as a covariate to assess their impact on inferences. This had little impact on our major conclusions and so we assumed proportion data were similar to effect sizes derived from other measurement types (see Appendix S1, Section 6.2). A few studies conducted experimental manipulations under fluctuating conditions, but for comparison across studies we focused on constant temperature treatments. In addition, several studies used more than two temperature treatments, in which case we extracted only the extreme temperatures provided within the range of minimum-maximum mean monthly temperatures in springsummer. We did this to avoid introducing a form of nonindependence in our data through the use of shared temperature treatments when calculating effect sizes (Noble et al., 2017a). We acknowledge that some studies included were on populations that were part of experimental evolution experiments reared in the laboratory at specific constant temperatures. The impact of this on phenotypic variance is not entirely clear if the temperature manipulation was conducted using the conditions the population were reared at previous to experimental evolution (see Appendix S1, Section 6.3 for a more thorough discussion of this problem). However, we dealt with this issue to some extent by analysing magnitudes of variance difference (see Section VII.2). Finally, we were conservative by only using data from treatments where there was potential for sexual selection to occur (e.g. multiple males and/or females competing) and excluded data from treatments of single-pair mating experiments.

\section{(2) Effect size statistics - comparing variance in fitness}

We compared how temperature impacted both the mean and variance across experimental groups using the log response ratio $(\operatorname{lnRR})$, the $\log$ variance ratio $(\operatorname{lnVR})$ and the $\log$ coefficient of variation ratio (lnCVR) (for effect size equations see Nakagawa et al., 2015). We were most interested in how variance in reproductive success, or traits known to be directly related to reproductive success, change as a function of temperature as this is a more direct test of temperature effects on sexual selection, given it is a measure of the opportunity for sexual selection. Hence, we focus mainly on $\ln V R$ and $\operatorname{lnCVR}$ in our meta-analysis, but we report the results from $\ln R R$ in Appendix S1. We used $\operatorname{lnVR}$ as a direct estimate of the difference in trait variance. However, given that $\ln V R$ does not account for mean variance relationships that existed in our data, we used lnCVR to estimate how variance in reproductive success changes independent of changes in average fitness/trait between temperature treatments (Nakagawa et al., 2015). In all cases, when using directional effect sizes (i.e. not absolute magnitude) positive effect sizes indicated that higher temperature treatments had a larger variance compared to lower temperature treatments, whereas negative effect sizes indicated the opposite.

\section{(3) Moderator variables}

We collected a number of variables that we, a priori, predicted would moderate the impact of temperature on sexual selection within and across studies. These included: (i) the 
temperature difference between experimental treatments (continuous variable) - larger temperature differences between treatments are likely to lead to greater effect sizes; (ii) the sex of the sample - we predict stronger sexual selection and effects of temperature in males compared to females (Janicke et al., 2016); (iii) life-history stage at which the temperature manipulation took place (i.e. 'lifetime', 'juvenile/ early', 'adults') - given that temperature can impact development that subsequently affects reproductive traits and success; and $(i v)$ whether the trait in question was a 'direct' or 'indirect' proxy for sexual selection, where 'direct' estimates were those measuring some aspect of mating or reproductive success and 'indirect' estimates were those traits linked to mating or reproductive success. Finally, in some cases, 'hot' or 'cold' temperature treatments were outside of the natural range (see Section VII.1), so we also classified all effect sizes depending on whether the temperature treatment was 'natural' or 'stressful'. Briefly, if experimental individuals came from a natural population, treatments were categorised as 'natural' versus 'stressful' depending on whether they were within the maximum-minimum temperature range for that population. Given that studies varied in terms of whether temperatures were stressful or not, and the types of traits were different across studies (not all were direct measures of fitness), we could not calculate more direct measures of environmental stress (e.g. change in reproductive output across temperature). If experimental individuals came from populations adapted to laboratory conditions (i.e. kept for more than 100 generations under a constant temperature regime), we considered temperature treatments $>4^{\circ} \mathrm{C}$ away from their normal rearing temperature as stressful. In two cases, experimental individuals came from long-term laboratory populations reared at a given temperature that were then subject to a short-term ( $<20$ generations; Plesnar-Bielak et al., 2012, 2018) experimental evolution study at a different temperature; in these two cases we considered the long-term rearing temperature as the 'ancestral' temperature.

\section{(4) Meta-analysis}

We used multi-level meta-analytic (MLMA) and multi-level meta-regression (MLMR) models in the $\mathrm{R}$ package metafor (Viechtbauer, 2010) to test temperature effects on sexual selection and to explore drivers of effect size variation (Hadfield \& Nakagawa, 2010; Nakagawa \& Santos, 2012). In all models we included a random effect of study and species and also included an observation-level random effect to estimate residual variance, given that metafor does not estimate one by default. While we had a diversity of species in our data set, these were taxonomically biased towards insects and we had difficulty resolving the phylogenetic position of most of the taxa in our data set (tested with TimeTree.org - only $5 / 15$ species were identified) - we therefore were limited in our ability to control for phylogeny in our analyses (Chamberlain et al., 2012; Noble et al., 2017a). Instead, we used a phylogeny that was based only on topological relationships between taxa. We used Grafen's method (Grafen, 1989) to create phylogenetic correlation matrices and included these matrices in our models as a sensitivity analysis. Including phylogenetic correlation matrices or not did not impact our results (see Appendix S1, Section 6.1) and so we just controlled for species in our models by including a random effect of species. We also assessed publication bias by looking at funnel plots and found little evidence for bias that may impact our results (see Fig. S1 in Appendix S1, Section 5).

In addition to estimating the overall directional mean effect across studies from our MLMA models, we estimated measures of effect size heterogeneity (Higgins \& Thompson, 2002; Nakagawa \& Santos, 2012). We estimated the between-study heterogeneity $\left(\right.$ Het $_{\text {stdy }}$ : proportion of variation in effects from shared studies), species heterogeneity (Het $t_{\mathrm{sp}}$ : proportion of variation in effects from shared species) and total sampling heterogeneity $\left(H_{e t} t_{\text {err }}\right.$ : the proportion of variation in effects resulting from sampling variance). Het $t_{\mathrm{err}}$ describes how much variation in effects can simply be explained by changes in sample sizes (i.e. related to sampling variance) across studies as opposed to real biological variation. Directional predictions regarding the role of temperature on sexual selection processes depends on many factors, which make clear directional predictions on how variance is expected to change challenging. As such, we estimated the overall magnitude of variance difference across temperature treatments. To avoid bias in these estimates, we modelled the directional effect sizes assuming a normal distribution and then subsequently transformed this mean estimate using the folded normal distribution, to get the mean absolute magnitude (sensu Morrissey, 2016). To estimate uncertainty around this estimate, we used a Bayesian approach with MCMCglmm (Hadfield, 2010), and applied the entire posterior distribution of mean estimates to the folded normal.

We tested whether our hypothesised moderators explained heterogeneity in effects using our MLMR models. Given our limited sample size (males: $\mathcal{N}=31$ effects from 14 studies; females: $\mathcal{N}=18$ effects from 9 studies), we limited the number of moderators fit to each model to two, and modelled the sexes separately as subset analyses. We ended up not modelling developmental stage given that most of the studies manipulated temperature over the lifetime of the animals. A full presentation on the results and models run can be found in Appendix S1, sections 2, 3 and 6. In all cases we present $95 \%$ credible/confidence intervals around our mean effect sizes. Intervals not overlapping each other and zero are considered significant.

\section{(5) Meta-analysis results and discussion}

Experimental studies assessing the effects of temperature on sexual selection are currently biased towards insects (16/19 studies), with only one on arachnids and two on fish. Between-study heterogeneity was moderate to high for males $\left(\right.$ Het $\left._{\text {stdy }}: \ln \mathrm{VR}=0.77, \operatorname{lnCVR}=0.34\right)$ and small to non-existent for females $\left(\right.$ Het $\left._{\text {stdy }}: \operatorname{lnVR}=0.13, \operatorname{lnCVR}=0\right)$. Nonetheless, there was still a moderate amount of heterogeneity beyond simple sampling variance (Het $t_{\text {err }}$ : males - 
$\operatorname{lnVR}=0.16, \operatorname{lnCVR}=0.31 ;$ females $-\operatorname{lnVR}=0.33$, $\operatorname{lnCVR}=0.31$ ).

The magnitude of effects (i.e. non-directional effect of temperature on variance) was moderate, suggesting that temperature does indeed influence direct and indirect measures of sexual selection (Fig. 2). By contrast, the overall directional mean effect on variance in all cases did not differ from zero (although there does seem to be a trend whereby higher temperatures are associated with increased variance). Therefore, there was no clear directional impact of temperature on sexual selection (Fig. 2). At an average temperature difference between treatments of $7.5^{\circ} \mathrm{C}$, male variance $(\operatorname{lnVR})$ decreased at the higher temperature relative to the lower temperature if the temperature manipulation was stressful or if it was a direct measure of reproductive fitness (Fig. 2A). However, this effect was driven by changes in the mean phenotype and when controlling for the mean there was no significant change in variance resulting from stressed or natural conditions (Fig. 2B). By contrast, when controlling for the mean, traits indirectly associated with reproductive success showed an increased variance relative to lower temperatures (Fig. 2B). Results from females generally mirrored results from males, except it was not possible robustly to compare direct and indirect fitness measures given that indirect measures came from only one study. An interesting difference from males is that, when accounting for changes in the mean, stressful temperatures seemed to explain the observed increase in the variance of reproductive success in females (Fig. 2D). This may indicate that temperature effects on the variance of female reproductive success are largely mediated by environmental stress. A recent model predicts exactly this outcome, due to the fact that fecundity selection on females is relatively 'hard', so that an increase in female variability in fitness is expected with greater environmental stress (Martinossi-Allibert et al., 2019a). By contrast, selection on males is relatively 'soft' because they compete against other 'maladapted' males and their fitness is mainly constrained by limited access to females and overall female productivity (Martinossi-Allibert et al., 2019a). In accordance with this idea, we found that temperature effects on males did not seem to be driven by stressful temperature treatments.

Our meta-analysis offers evidence in support of the idea that temperature may modulate sexual selection. As evidenced by our systematic search, available data are scant and come mostly from studies that did not aim to measure the relationship between temperature and sexual selection. We did find a few other observational studies reporting correlations between temperature and sexual selection in wild populations (the most relevant are discussed in Section I), but interpretation in these cases is problematic due to the large number of confounding variables (e.g. humidity, precipitation). In addition, we failed to include one relevant study (Santos et al., 2018) which clearly showed that temperature disrupts mating patterns, which impacts sexual selection intensity in Artemia franciscana. In this study, the authors measured selection differentials based on size differences between mated and unmated individuals. Body size has been shown to be under sexual selection in this species, but we decided to act conservatively by eliminating this from our meta-analysis because body size is also under strong natural selection and is directly influenced by temperature. As stressed herein, and for the reasons stated, available studies were surprisingly scarce. This made it difficult for our meta-analysis to evaluate properly the interesting questions arising from our review, such as the existence of sex-specific temperature effects on sexual selection and a general trend in the directionality of such effects (D. Berger, J. Stanberg \& R. J. Walters, in preparation). We hope that our work spurs further studies into the connections between temperature and sexual selection, which will allow for more powerful meta-analyses.

\section{THE PATH AHEAD: STUDYING THE INTERPLAY BETWEEN TEMPERATURE, SEXUAL SELEGTION AND POPULATION VIABILITY}

\section{(1) Considering temperature effects on sexual selection}

We suggest that studies aimed at understanding the link between sexual selection and temperature should focus not only on fluctuations in mean temperature, but also on the role of maximum/minimum temperatures and temperature variability. Spermatogenesis seems to be generally vulnerable to peak temperatures across different taxa (Walsh et al., 2019), suggesting that considering maximum/minimum temperatures may be particularly important when studying temperature effects on post-copulatory processes. For example, a recent study in the flour beetle (Tribolium castaneum) found that experimental heat-waves compromise sperm function even if they occur after sperm is stored in the female spermatheca, and that successive heat-waves can render males infertile (Sales et al., 2018). Sales et al. (2018) also found temperature-induced trans-generational effects in line with those reported in other species (Gasparini et al., 2018).

Studying the role of temperature fluctuations may also provide insight into the maintenance of additive and cryptic genetic variation, and generally on how sexual selection operates in complex environments (Miller \& Svensson, 2014). Due to circadian, intra-seasonal and inter-seasonal temperature variation, many (if not most) organisms will be reproductively active under a range of environmental temperatures in the wild (i.e. reproductive operational thermal range). This means that sexual selection will unfold in a constantly varying thermal environment which, as long as there are inter-individual differences in genotype-by-environment interactions, can both increase or decrease the opportunity for sexual selection, as well as change the relative importance and integration between pre- and post-copulatory processes. In a constantly fluctuating environment, males that are particularly successful at competing for reproduction at the mean temperature within its operational range may also happen to be better competitors at other temperatures (e.g. high 
(A)
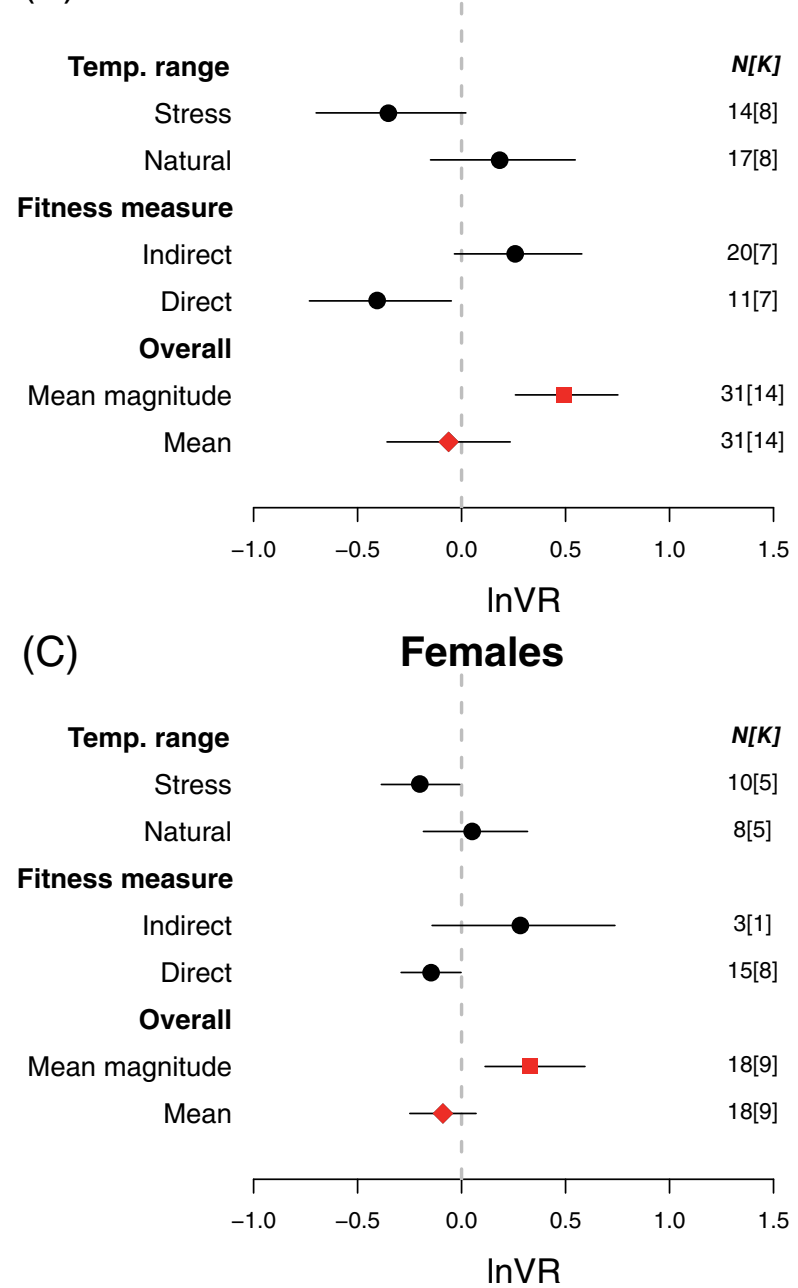

(B)

Males

Stress

Natural

Fitness measure

Indirect

Direct

Overall

Mean magnitude

Mean

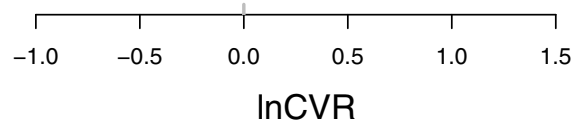

(D)

Females

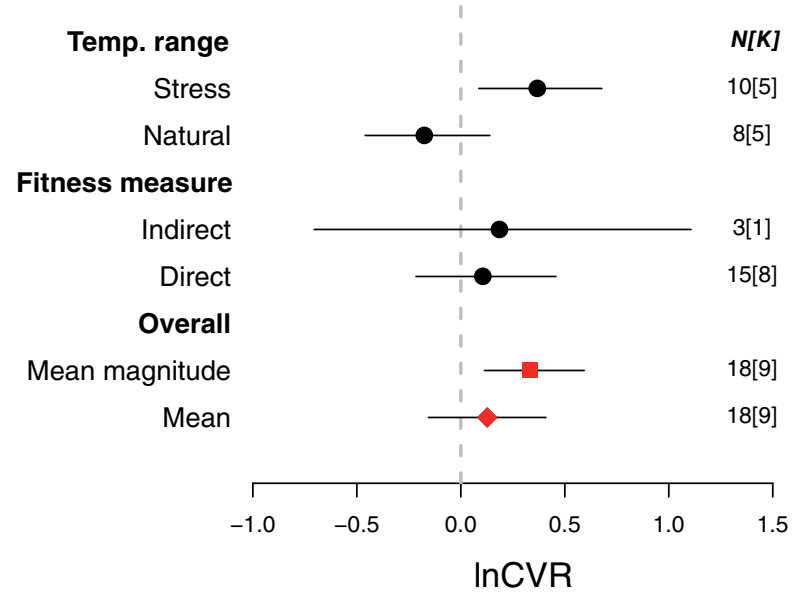

Fig 2. Meta-analytic means for a temperature treatment difference of approximately $7.5^{\circ} \mathrm{C}$ across MLMA and MLMR models for the $\log$ variance ratio $(\operatorname{lnVR})$ and the $\log$ coefficient of variation ratio $(\operatorname{lnCVR})$ for males and females. $\mathcal{N}$, total number of effect sizes; $k$, total number of studies. Mean estimates and 95\% credible/confidence intervals are provided. Subset analyses exploring the impact of various moderators on $\ln \mathrm{VR}$ and $\ln \mathrm{CVR}$ are provided (black circles), along with the overall meta-analytic mean (red diamond) and the mean magnitude of effect size differences between treatments (red square).

phenotypic plasticity; Gilchrist, 1995). That is, good males may tend to be even better in fluctuating scenarios, perhaps due to being in a generally better condition and/or having a higher degree of adaptive phenotypic plasticity. Hence, the variability in net male mating/reproductive success will be higher when considering intra- and inter-sexual selection across the whole reproductive operational thermal range (and not just the mean temperature, as is commonly done in laboratory experiments) leading to higher opportunity for sexual selection/selection $\left(I_{\mathrm{s}} / I\right.$; Fig. 3A). For example, in the red mason bee (Osmia bicornis) female choice is partly based on male vibrational signals, which are affected by the marked temperature changes that this species experiences during reproduction in the wild. In contrast to males that are rejected by females, vibrational signals by male bees that are accepted by females are far less influenced by temperature changes (Conrad et al., 2017). An added consequence of this type of scenario is that sexual selection traits that are particularly resilient to temperature will likely experience consistent selection across mating patches representing different thermal conditions, and hence steeper net selection gradients at the population level. By contrast, selection on more labile traits may vary in intensity and direction across mating patches that vary in their thermal conditions, and hence experience weaker selection pressures. Alternatively, due to temperature-dependent constraints and/or trade-offs in underlying mechanisms, males good at competing at a given temperature may be relatively less competitive at other temperatures (e.g. 'thermal specialists'; Gilchrist, 1995), leading to the opposite scenario (Fig. 3B). Yet another alternative is the coexistence of both thermal generalists and specialists in the same population, with frequency- 

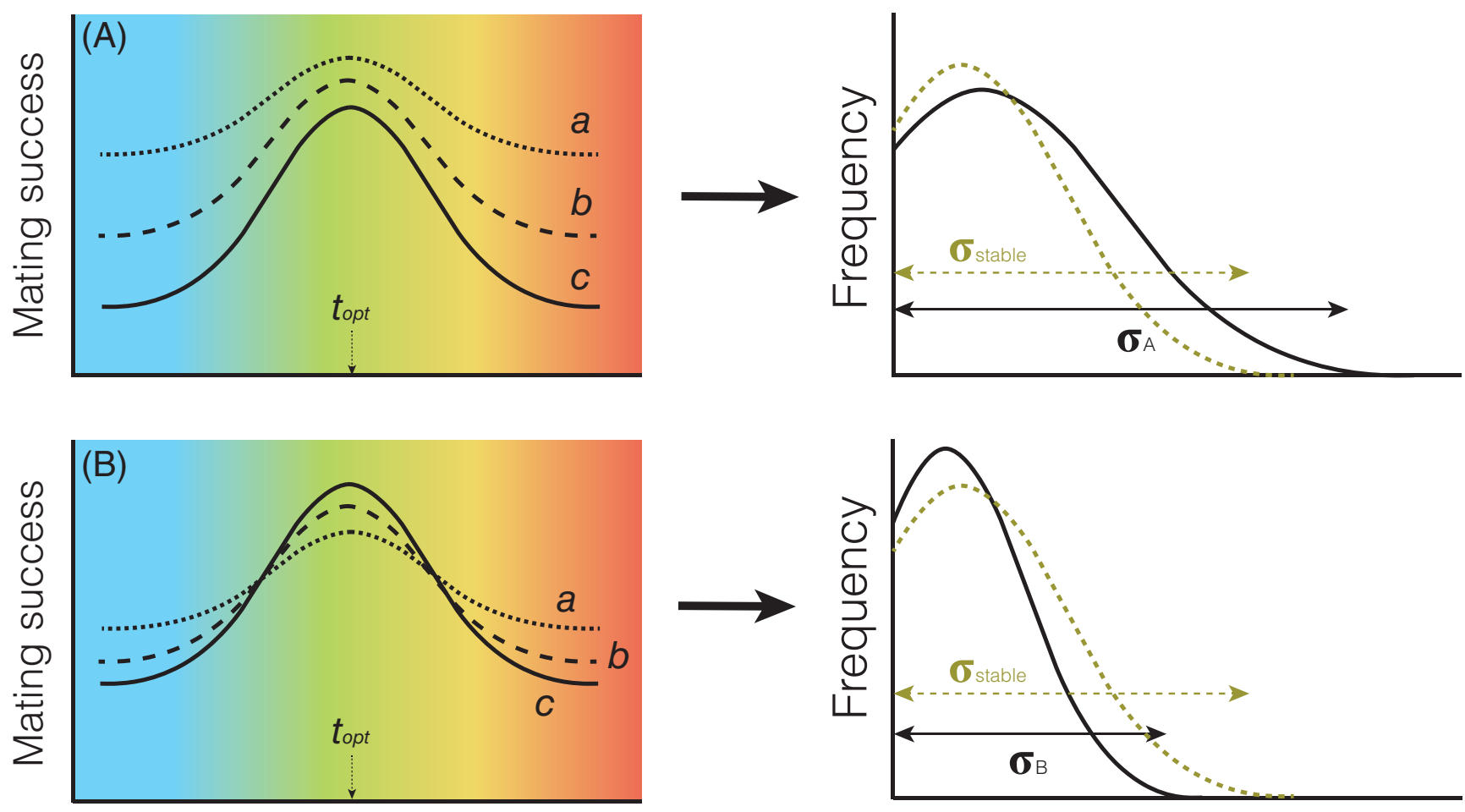

Temperature

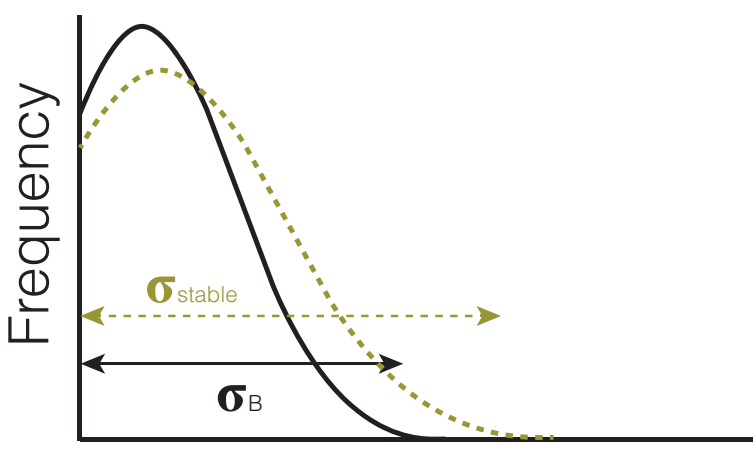

Fitness

Fig 3. Depending on the shape of reaction norms to temperature fluctuations during the reproductively active period of the day/ season, temperature effects on mating success may increase (A) or decrease (B) the opportunity for selection. For simplicity, here we consider an equiprobable distribution of temperatures across this range. In A, high-quality competitors at the mean temperature $\left(t_{\text {opt }}\right)$ also adjust better to temperature fluctuations (higher adaptive phenotypic plasticity) and maintain a more stable mating success and/or reproductive success across this thermal range. As a consequence, male variability in fitness $(\sigma)$ is higher in fluctuating $\left(\sigma_{\mathrm{A}}\right.$ and solid black line) versus stable $\left(\sigma_{\text {stable }}\right.$ and dotted gold line) thermal environments, and temperature effects increase the opportunity for sexual selection $\left(I_{\mathrm{s}}\right)$ and/or the opportunity for selection at large $(I)$. In B, individuals with high mating and/or reproductive success at the mean temperature fare worse at other temperatures (e.g. due to the existence of trade-offs and/ or constraints in underlying mechanisms across temperatures). The variability in mean male fitness is hence reduced when considering intra- and inter-sexual selection across the whole thermal environment $\left(\sigma_{\mathrm{B}}\right.$; solid black line) versus the mean $\left(\sigma_{\text {stable; }}\right.$; dotted gold line) thermal environment, and so are $I_{\mathrm{s}}$ and/or $I$.

dependent effects that will necessarily rest largely on prevailing temperature conditions. This type of evolutionary scenario can favour diverging strategies across the operational thermal range, and hence contribute to the maintenance of genetic variability (see Fig. 3B). As a case in point, Svensson et al. (2020) recently showed that temperature drives prereproductive selection in the female-colour-polymorphic damselfly Ischnura elegans, such that the frequency of female morphs varies geographically due to differential temperature sensitivity and maturation rates across morphs.

In the above cases, sexual selection will ultimately maximise mating/reproductive success over the whole range of reproductive operational temperatures, which underscores the need to integrate different episodes/mechanisms of sexual selection to consider the total opportunity for sexual selection (Miller \& Svensson, 2014; Evans \& Garcia-Gonzalez, 2016). Competition across fluctuating environments is also bound to affect covariation between pre/post and/or intra/inter-sexual mechanisms (Evans \& Garcia-
Gonzalez, 2016) if different mechanisms are affected differently by temperature; e.g. spermatogenesis and sperm-competition processes may be more vulnerable to high temperatures (see above). Understanding how temperature affects different sexual selection mechanisms (i.e. inter- versus intra-sexual and pre- versus post-copulatory), and in particular genotype-by-environment interactions, may thus further our understanding of sexual selection in wild populations.

Importantly, coarse-grained temperature fluctuations may have different consequences for sexual selection, as they may lead to maximisation of geometric (rather than arithmetic) mean fitness. Fine-grained temperature variation (as discussed so far) reflects fluctuations in temperature that individual organisms experience across their reproductive lifespan, whereas coarse-grained temperature variation reflects fluctuations that are only experienced across generations (e.g. inter-seasonal variation in non-iteroparous species). In the latter case, temperature variation poses the classic problem of dealing with unpredictable future environments 
(Levins, 1968). Knowing whether such environmental fluctuations lead to different bet-hedging strategies (Slatkin, 1974) in the context of sexual selection would be key to understanding the causes and consequences of sexual selection in complex environments. For example, some sexual selection mechanisms are bound to be more vulnerable to temperature changes than others (e.g. post-copulatory processes dependent on ejaculate size or quality at high temperatures). As a consequence, in a coarse-grained temporal scale, sexual selection may give rise to conservative bet-hedging strategies by favouring investment in sexual selection traits that are more robust to temperature changes. Thus, strategies that may appear suboptimal when considering intra- and intersexual selection within the lifetime of individuals (i.e. lower mean arithmetic fitness) may actually be advantageous when considering selection acting across multiple generations (i.e. higher mean geometric fitness; e.g. Yasui \& GarciaGonzalez, 2016).

An interesting feature of ectotherms that should be taken into account when studying responses to temperature is that thermal fitness curves of ectotherms are highly asymmetric, such that fitness drops faster with increasing than decreasing temperatures away from the optimum (Martin \& Huey, 2008). This can have biologically relevant consequences. For example, the predicted optimal behaviour when fitness functions are non-linear will depend drastically on the variance and skewness of the fitness-temperature curve (Martin \& Huey, 2008). Finally, an interesting question that we have already touched upon is whether we may expect directional effects of temperature on sexual selection. Generally speaking, we have argued above that we may expect the relationship between temperature and sexual selection to rest largely on the physiology, morphology, behaviour and mating system of each species.

However, some biological processes will tend to exhibit monotonic relationships with temperature that are relevant to sexual selection, potentially driving directional effects. Given that temperature constrains certain fundamental biochemical properties it has recently been proposed that mutations will have increasing fitness effects, and hence lead to stronger selection, with increasing temperatures (D. Berger, J. Stanberg \& R. J. Walters, in preparation). Similarly, some of the effects of temperature on mating systems may be expected to modulate sexual selection consistently in the same direction. For example, temperature increases may lead to longer reproductive seasons, which in some species may relax sexual selection by spreading competition over a longer time frame (Monteiro \& Lyons, 2012). Detecting directional effects of temperature on sexual selection is an exciting prospect, as it may allow us to identify previously unrecognised taxonomic (e.g. ectotherms versus endotherms) and/or macro-evolutionary (e.g. tropics versus temperate zones) patterns in sexual selection processes/traits. In other species, however, longer reproductive seasons could intensify and/or change the form of sexual selection. For example, in harvestmen (Opiliones) the length of the breeding season is mainly affected by the number of warm months, and longer breeding seasons increase the probability of resource defence polygyny and the magnitude of sexual dimorphism (Machado et al., 2016).

\section{(2) Considering eco-evolutionary feedback}

As we have pointed out above, temperature effects on sexual selection may feed back to impact population viability and evolvability. The evidence that populations where sexual selection is present or intense adapt faster and are more effective in tracking the environment keeps accumulating (Parrett et al., 2019). A step forward would be to provide evidence that temperature effects on sexual selection can be strong enough to impact population viability and/or evolvability in a meaningful way. As far as we know, direct evidence for this is almost completely absent except for a few studies drawing indirect connections between temperature, sexual conflict intensity and population productivity (Berger et al., 2014; García-Roa et al., 2019; Martinossi-Allibert et al., 2019b). To bridge this gap, we suggest that future studies looking at the relationship between sexual selection and temperature should try to incorporate population measures of viability/ evolvability, or at least attempt to extrapolate fitness consequences at the level of individuals to populations, ideally under different population demography scenarios (Edward et al., 2010).

\section{(3) Where and how to study temperature effects on sexual selection}

While the ideas described so far are in principle generally applicable to a wide range of animals, it is obvious that some taxa, such as ectotherms, will be more vulnerable to temperature effects on sexual selection. In consequence, we would generally predict much stronger temperature effects on insects, reptiles, amphibians and fish than on, say, mammals or birds. For this reason, future work on ectotherms is bound to bring a sharper focus on the links between temperature and sexual selection. However, we stress the need to explore as wide a variety of taxa as possible if the aim is to understand what mechanisms of sexual selection are impacted by temperature and how.

Sexual selection in plants, too, is likely to be affected by temperature both directly (e.g. physiology; Hedhly, Hormaza, \& Herrero, 2009) and indirectly, via its effect on pollinators through any of the pathways described above. More specifically, temperature may affect intra-sexual selection in plants at different levels: during competition for pollination, via its effects on pollen receipt and removal (Murcia, 1990), the successful transfer of pollen to stigmas (e.g. if temperature affects insect activity and/or spatial range; Nielsen et al., 2017), and more generally by affecting plant-insect interactions (DeLucia et al., 2012). After pollination, temperature is one of the main determinants of pollen performance, potentially affecting the opportunity for sperm competition (i.e. post-pollination intra-sexual selection; Mazer et al., 2018). In addition, temperature can affect the amount of time 
outcrossing flowers stay fresh and receptive (Arroyo et al., 2013), modulating the possibility of receiving pollen from multiple donors and hence the potential for post-pollination intra-sexual competition. Flower size and morphology has also been shown to be dependent on temperature in some species (Murcia, 1990), and stigma size and style length can intensify gametophytic competition (Travers \& Shea, 2001; Mazer et al., 2018).

Regardless of the specific taxa targeted, we suggest studies will need to consider the effects of adult versus developmental thermal environments, constant versus fluctuating temperature regimes (or heat/cold shocks), and the role of behaviour in buffering temperature effects on reproductive parameters and mating systems in natural populations (and thus sexual selection processes). More specifically, there is much need for realistic experimental studies, ideally on individuals from wild populations, that manipulate temperature within their natural range (i.e. daily, intra-seasonal and inter-seasonal fluctuations) and ask how such manipulation affects their mating system, ensuing sexual selection and/or sexual conflict intensity, and if possible population viability. Similarly useful will be comprehensive field studies that seek to: $(\imath)$ identify differences in traits among populations (e.g. secondary sexual traits); (ii) document whether such differences can be explained by variation in the strength and/or form of sexual selection, the relative importance of inter- versus intra-sexual selection, and the relative weight of pre-copulatory versus post-copulatory episodes of selection; (iii) document the causes and underlying mechanisms of sexual selection (e.g. social interactions, OSR, etc.); (iv) show that temperature changes causal interactions in ways that modify selection (e. g. weaker social interactions in hot climates); and (v) study the broad consequences of the impact of temperature on sexual selection (e.g. in terms of the opportunity for selection/ sexual selection) and, when possible, on population viability. Given that temperature effects are best tested using carefully controlled experimental manipulations at the population level it will likely mean that suitable invertebrate, plant and a sample of small-vertebrate systems will contribute most to our understanding of how temperature impacts sexual selection. This taxonomic bias may be challenging to deviate from without creative ways to manipulate and isolate temperature in certain systems.

\section{GONGLUSIONS}

(1) Given the relevance of sexual selection for individual phenotypes and population fates, a central question in evolutionary biology is to disentangle why sexual selection and sexual conflict vary so much in their form, strength and outcomes across taxa. The role of ecology in explaining sexual selection has been considered prominent so far; albeit less so in the case of sexual conflict. Surprisingly, though, the specific role of temperature, perhaps the most salient abiotic ecological factor at a global taxonomic scale, has been relatively ignored.

(2) Temperature is a fundamental abiotic factor with a strong impact on organism physiology, morphology and behaviour. In the wild, environmental temperature exhibits frequent and significant variation at both the spatial scale (i.e. micro- and macroecological) and temporal scale (i.e. circadian, seasonal and inter-seasonal). However, the question whether temperature can modulate sexual selection and sexual conflict, and the consequences in terms of potential eco-evolutionary feedback on population viability, has been largely neglected.

(3) We currently lack the empirical data necessary to understand: (i) the degree to which temperature may affect sexual selection and sexual conflict in nature; (ii) the mechanisms underlying such effects, in terms of how temperature modulates secondary sexual traits, male/female reproductive success and mating systems; (iii) how such effects unfold in the short (phenotypic plasticity) and the long (evolutionary) term; and (iv) the degree to which such effects may impact population viability/extinction risk.

(4) Here, we knit together existing theory and empirical data to weave a framework on how temperature may modulate sexual selection through direct and indirect effects on sexually selected traits and preferences, population dynamics, mating systems, constraints and trade-offs and correlated abiotic factors. Via these same pathways, temperature may also be a fundamental modulator of sexual conflict, which is not only an increasingly appreciated evolutionary mechanism to understand the evolution of male and female adaptations and life-histories, but a particularly direct link between sexual selection and population viability.

(5) While current studies on the impact of rapid environmental changes in temperature (e.g. due to global warming) on population extinction focus mainly on first-order effects of rising temperatures on population viability, this approach ignores potential feedbacks on processes mediating sexual selection. Beyond directly affecting population viability, we suggest that rising temperatures may modulate sexual selection in ways that can both negatively (e.g. if rising temperatures slow sexual selection and, with it, the ability to purge mutations and/or viability of populations) or positively (e.g. if rising temperatures decrease sexual conflict, and with it, sex load) affect population fitness.

(6) To evaluate the general idea that sexual selection may be modulated by temperature, we performed a metaanalysis of existing evidence (mostly from studies not directly aimed at studying this link) and thereby provide preliminary evidence that temperature can indeed modulate sexual selection within a biologically relevant range.

(7) We conclude that a priority for the immediate future is to explore fundamental questions about the interplay 
between temperature and sexual selection, with respect to both short-term plastic changes (i.e. behavioural plasticity), inter-generational and trans-generational effects, evolutionary responses, and the consequences that such processes have for population viability. We highlight ways in which future studies may bridge these gaps in knowledge.

\section{AGKNOWLEDGEMENTS}

We thank Tobias Uller, Manuel Serra, three anonymous reviewers and in particular David Berger for insightful comments on previous drafts of this manuscript. P.C. was supported by a "Plan Nacional I+D+i Excelencia" grant (CGL2017-89052-P), co-funded by the Agencia Estatal de Investigacion and the European Regional Development Fund, a Generalitat Valenciana "Excellence of Young Researchers" SEJI grant (SEJI/2018/037), and by a 2018 Leonardo Grant for Researchers and Cultural Creators, from the BBVA Foundation. F.G.-G. was supported by a MINECO "Plan Nacional I + D + i Excelencia" grant (CGL2016-76173-P) co-funded by the Agencia Estatal de Investigacion and the European Regional Development Fund, and a CSIC start-up grant (201730I034). D.W.A.N. was supported by an ARC Discovery Early Career Research Award (DE150101774) and UNSW VC Fellowship.

\section{AUTHOR GONTRIBUTIONS}

P.C. conceived this paper; P.C., R.G.-R. and F.G.-G. discussed and developed its conceptual framework; P.C., R. G.-R. and D.W.A.N. conducted the systematic search; D. W.A.N. conducted the meta-analysis; P.G., R.G.-R., F.G.G. and D.W.A.N. wrote the paper.

\section{REFERENGES}

References marked with asterisks were included in the meta-analysis.

Abram, P. K., Borvin, G., Moiroux, J. \& Brodeur, J. (2017). Behavioural effects of temperature on ectothermic animals: unifying thermal physiology and behavioural plasticity. Biological Reviews of the Cambridge Philosophical Society 92(4), 1859-1876.

Agrawal, A. F. (2001). Sexual selection and the maintenance of sexual reproduction. Nature 411(6838), 692-695.

Andersson, M. (1994). Sexual Selection. Princeton University Press, Princeton.

Arbuthnott, D. \& Whitlock, M. C. (2018). Environmental stress does not increase the mean strength of selection. Fournal of Evolutionary Biology 31(10), 1599-1606.

Arbuthnott, D., Dutton, E. M., Agrawal, A. F. \& Rundle, H. D. (2014). The ecology of sexual conflict: ecologically dependent parallel evolution of male harm and female resistance in Drosophila melanogaster. Ecology Letters 17(2), 221-228.

Arnqvist, G. \& Rowe, C. (2005). Sexual Conflict. Princeton University Press, Princeton.

Arngvist, G. \& Tuda, M. (2010). Sexual conflict and the gender load: correlated evolution between population fitness and sexual dimorphism in seed beetles. Proceedings of the Royal Society B: Biological Sciences 277(1686), 1345-1352.

Arroyo, M. T., Dudley, L. S., Jespersen, G., Pacheco, D. A. \& Cavieres, L. A. (2013). Temperature-driven flower longevity in a high-alpine species of Oxalis influences reproductive assurance. New Phytologist 200(4), 1260-1268.

Beckers, O. M. \& Schul, J. (2008). Developmental plasticity of mating calls enables acoustic communication in diverse environments. Proceedings of the Royal Society B: Biological Sciences 275(1640), 1243-1248.
Berger, D., Walters, R. \& Gotthard, K. (2008). What limits insect fecundity? Body size- and temperature-dependent egg maturation and oviposition in a butterfly. Functional Ecology 22(3), 523-529.

Berger, D., Bauerfeind, S. S., Blanckenhorn, W. U. \& Schafer, M. A. (2011). High temperatures reveal cryptic genetic variation in a polymorphic female sperm storage organ. Evolution 65(10), 2830-2842.

Berger, D., Grieshop, K., Lind, M. I., Goenaga, J., Maklakov, A. A. \& Arngvist, G. (2014). Intralocus sexual conflict and environmental stress. Evolution 68(8), 2184-2196.

Berger, D., Martinossi-Allibert, I., Grieshop, K., Lind, M. I., Maklakov, A. A. \& ARNQvist, G. (2016). Intralocus sexual conflict and the tragedy of the commons in seed beetles. The American Naturalist 188(4), E98-E1 12.

Blackenhorn, W. U., Stillwell, R. C., Young, K. A., Fox, C. \& Ashton, K. G. (2006) When Rensch meets Bergmann: does sexual size dimorphism change systematically with latitude? Evolution 60, 2004-2011.

Bonduriansky, R. (2007). The evolution of condition-dependent sexual dimorphism. The American Naturalist 169, 9-19.

Bonduriansky, R. \& Chenoweth, S. F. (2009). Intralocus sexual conflict. Trends in Ecology and Evolution 24(5), 280-288.

Bonduriansky, R., Maklakov, A., Zajitschek, F. \& Brooks, R. (2008). Sexual selection, sexual conflict and the evolution of ageing and life span. Functional Ecology 22(3), 443-453.

Brown, J. H., Gillooly, J. F., Allen, A. P., Savage, V. M. \& West, G. B. (2004). Toward a metabolic theory of ecology. Ecology 85(7), 1771-1789.

Bubliy, O. A. \& Loeschcke, V. (2002). Effect of low stressful temperature on genetic variation of five quantitative traits in Drosophila melanogaster. Heredity 89, 70-75.

Cally, J. G., Stuart-Fox, D. \& Holman, L. (2019). Meta-analytic evidence that sexual selection improves population fitness. Nature Communications 10(1), 2017.

Candolin, U. \& Heuschele, J. (2008). Is sexual selection beneficial during adaptation to environmental change? Trends in Ecology \& Evolution 23(8), 446-452.

Candolin, U., Tukiainen, I. \& Bertell, E. (2016). Environmental change disrupts communication and sexual selection in a stickleback population. Ecology 97(4), 969-979.

Chamberlain, S. A., Hovick, S. M., Dibble, C. J., Rasmussen, N. L., Van Allen, B. G., Maitner, B. S., Ahern, J. R., Bell-Dereske, L. P., Roy, C. L., Meza-Lopez, M. Carrillo, J., Siemann, E., Lajeunesse, M. J. \& Whitney, K. D. (2012). Does phylogeny matter? Assessing the impact of phylogenetic information in ecological meta-analysis. Ecology Letters 15(6), 627-636.

Chapman, T., Liddle, L. F., Kalb, J. M., Wolfner, M. F. \& Partridge, L. (1995). Cost of mating in Drosophila melanogaster females is mediated by male accessory gland products. Nature 373(6511), 241-244.

Clark, R. A., Fox, C. J., Viner, D. \& Livermore, M. (2003). North Sea cod and climate change - modelling the effects of temperature on population dynamics. Global Change Biology 9, 1669-1680.

Clarke, A. (2004). Is there a universal temperature dependence of metabolism? Functional Ecology 18, 252-256.

Connallon, T. \& Clark, A. G. (2014). Evolutionary inevitability of sexual antagonism. Proceedings of the Royal Society B: Biological Sciences 281(1776), 20132123.

Connallon, T. \& Hall, M. D. (2016). Genetic correlations and sex-specific adaptation in changing environments. Evolution 70(10), 2186-2198.

Connallon, T. \& Hall, M. D. (2018). Environmental changes and sexually antagonistic selection. $e$ LS. https://doi.org/10.1002/9780470015902.a0028171.

Conrad, T., Stocker, C. \& Ayasse, M. (2017). The effect of temperature on male mating signals and female choice in the red mason bee, Osmia bicornis (L.). Ecology and Evolution 7(21), 8966-8975.

Cornwallis, C. K. \& Uller, T. (2010). Towards an evolutionary ecology of sexual traits. Trends in Ecology and Evolution 25(3), 145-152.

Cotter, S. C., Simpson Stephen, J., Raubenheimer, D. \& Wilson, K. (2010). Macronutrient balance mediates trade-offs between immune function and life history traits. Functional Ecology 25(1), 186-198.

Cotton, S., Small, J. \& Pomiankowski, A. (2006). Sexual selection and conditiondependent mate preferences. Current Biology 16(17), R755-R765.

Coyne, J. A. \& Orr, A. H. (2004). Speciation. Sinauer Associates, Inc., Sunderland.

Cunningham, G. D., While, G. M. \& Wapstra, E. (2017). Climate and sex ratio variation in a viviparous lizard. Biology Letters 13(5), 20170218.

Darwin, C. (1871). The Descent of Man and Selection in Relation to Sex. John Murray, London.

De Block, M. \& Stoks, R. (2003). Adaptive sex-specific life history plasticity to temperature and photoperiod in a damselfly. Fournal of Evolutionary Biology 16(5), 986-995.

De Lisle, S. P., Goedert, D., Reedy, A. M. \& Svensson, E. I. (2018). Climatic factors and species range position predict sexually antagonistic selection across taxa. Philosophical Transactions of the Royal Society of London B: Biological Sciences 373(1757), 20170415.

Delcourt, M., Blows, M. W. \& Rundle, H. D. (2009). Sexually antagonistic genetic variance for fitness in an ancestral and a novel environment. Proceedings of the Royal Society B: Biological Sciences 276(1664), 2009-2014. 
Delucia, E. H., Nabity, P. D., Zavala, J. A. \& Berenbaum, M. R. (2012). Climate change: resetting plant-insect interactions. Plant Physiology 160(4), 1677-1685.

Donkin, I. \& Barres, R. (2018). Sperm epigenetics and influence of environmental factors. Molecular Metabolism 14, 1-11.

Dowling, D. K., Williams, B. R. \& Garcia-Gonzalez, F. (2014). Maternal sexual interactions affect offspring survival and ageing. Fournal of Evolutionary Biology 27(1), 88-97.

Du, W. G. \& SHINE, R. (2015). The behavioural and physiological strategies of bird and reptile embryos in response to unpredictable variation in nest temperature. Biological Reviews 90(1), 19-30.

*Dubey, A. \& Mishra, G. (2016). Influence of temperature on reproductive biology and phenotype of a ladybird, Menochilus sexmaculatus (Fabricius) (Coleoptera: Coccinellidae). Fournal of Thermal Biology 58, 35-42.

Edward, D. A., Fricke, C., Gerrard, D. T. \& Chapman, T. (2010). Quatifying the lifehistory response to increased male exposure in female Drosophila melanogaster. Evolution 65(2), 564-573.

Elliot, S. L., Blanford, S. \& Thomas, M. B. (2002). Host-pathogen interactions in a varying environment: temperature, behavioural fever and fitness. Proceedings of the Royal Society B: Biological Sciences 269(1500), 1599-1607.

EmLen, S. T. \& Oring, L. W. (1977). Ecology, sexual selection, and the evolution of mating systems. Science 197(4300), 215-223.

Engstrom, J. \& CAndolin, U. (2007). Human-induced water turbidity alters selection on sexual displays in sticklebacks. Behavioral Ecology 18(2), 393-398.

Evans, J. P. \& Garcia-GonZalez, F. (2016). The total opportunity for sexual selection and the integration of pre- and post-mating episodes of sexual selection in a complex world. Fournal of Evolutionary Biology 29(12), 2338-2361.

Evans, J. P., Wilson, A. J., Pilastro, A. \& Garcia-Gonzalez, F. (2019). Ejaculatemediated paternal effects: evidence, mechanisms and evolutionary implications. Reproduction 157(4), R109-R126.

*Fairbairn, D. J. (2005). Allometry for sexual size dimorphism: testing two hypotheses for Rensch's rule in the water strider Aquarius remigis. American Naturalist 166, S69-S84

FiELDS, P. A. (2001). Review: protein function at thermal extremes: balancing stability and flexibility. Comparative Biochemistry and Physiology A 129, 417-431.

Fogleman, J. C. (1979). Oviposition site preference for substrate temperature in Drosophila melanogaster. Behavior Genetics 9(5), 407-412.

*Fox, C. W., Stillwell, R. C., Wallin, W. G. \& Hitchcock, L. J. (2006). Temperature and host species affect nuptial gift size in a seed-feeding beetle. Functional Ecology 20, 1003-1011.

Fox, C. R., Stillwell, R. C. \& Moya-Larano, J. (2007). Variation in selection, phenotypic plasticity, and the ecology of sexual size dimorphism in two seedfeeding beetles. In Sex, Size and Gender Roles: Evolutionary Studies of Sexual Size Dimorphism (eds D. J. Fairbairn, W. U. Blackenhorn and T. Szekely). Oxford University Press, Oxford.

Gamelon, M., Grotan, V., Nilsson, A. L. K., Engen, S., Hurrell, J. W., Jerstad, K., Phillips, A. S., Rostad, O. W., Slagsvold, T., Walseng, B., Stenseth, N. C. \& SAETHER, B.-E. (2017). Interactions between demography and environmental effects are important determinants of population dynamics. Science Advances 3(2), e1602298.

Garcia-Gonzalez, F. \& Simmons, L. W. (2007). Paternal indirect genetic effects on offspring viability and the benefits of polyandry. Current Biology 17(1), 32-36.

García-Roa, R., Chirinos, V. \& Carazo, P. (2019). The ecology of sexual conflict: temperature variation in the social environment can drastically modulate male harm to females. Functional Ecology 33, 681-692.

Gasparini, C., Lu, C., Dingemanse Niels, J. \& Tuni, C. (2018). Paternal effects in a terrestrial ectotherm are temperature dependent but no evidence for adaptive effects. Functional Ecology 32(4), 1011-1021.

GAVRILETS, S. (2000). Rapid evolution of reproductive barriers driven by sexual conflict. Nature 403(6772), 886-889.

Gavrilets, S. (2014). Is sexual conflict an "engine of speciation"? Cold Spring Harbour Perspectives in Biology 6(12), a017723.

Gay, L., Hosken, D. J., Eady, P., Vasudev, R. \& Tregenza, T. (2010). The evolution of harm-effect of sexual conflicts and population size. Evolution 65(3), 725-737.

GERHARDT, C. H. (1978). Temperature coupling in the vocal communication system of the gray frog, Hyla versicolor. Science 199, 992-994.

Gerhardt, C. H. \& Mudry, K. M. (1980). Temperature effects on frequency preferences and mating call frequencies in the green treefrog, Hyla cinerea (Anura: Hylidae). Joumal of Comparative Physiology A 137, 1-6.

Gilbert, S. F., Bosch, T. C. \& Ledon-Rettig, C. (2015). Eco-Evo-devo: developmental symbiosis and developmental plasticity as evolutionary agents. Nature Reviews Genetics 16(10), 611-622.

GILCHRIST, G. W. (1995). Specialists and generalists in changing environments. I. Fitness landscapes of thermal sensitivity. The American Naturalist 146(2), 252-270.

Gillespie, S. R., Scarlett Tudor, M., Moore, A. J. \& Miller, C. W. (2014). Sexual selection is influenced by both developmental and adult environments. Evolution $\mathbf{6 8}$ (12), 3421-3432.
Gillooly, J. F., Brown, J. H., West, G. B., Savage, V. M. \& Charnov, E. L. (2001) Effects of size and temperature on metabolic rate. Science 293(5538), 2248-2251.

Gomez-Llano, M. A., Bensch, H. M. \& Svensson, E. I. (2018). Sexual conflict and ecology: species composition and male density interact to reduce male mating harassment and increase female survival. Evolution 72(4), 906-915.

Grafen, A. (1989). The phylogenetic regression. Philosophical Transactions of the Royal Society B: Biological Sciences 326, 119-157.

Grayson, K. L., Mitchell, N. J., Monks, J. M., Keall, S. N., Wilson, J. N. \& Nelson, N. J. (2014). Sex ratio bias and extinction risk in an isolated population of tuatara (Sphenodon punctatus). PLoS One 9(4), e94214.

Grazer, V. M. \& Martin, O. Y. (2012). Elevated temperature changes female costs and benefits of reproduction. Evolutionary Ecology 26(3), 625-637.

Greenfield, M. D. \& Medlock, C. (2007). Temperature coupling as an emergent property: parallel thermal effects on male song and female response do not contribute to species recognition in an acoustic moth. Evolution 61(7), 1590-1599.

Groot, A. T. \& ZizZari, Z. V. (2019). Does climate warming influence sexual chemical signaling? Animal Biology 69(1), 83-93.

Gunderson, A. R. \& LeAL, M. (2015). Patterns of thermal constraint on ectotherm activity. The American Naturalist 185(5), 653-664.

Gwynne, D. T. \& Simmons, L. W. (1990). Experimental reversal of courtship roles in an insect. Nature 346, 172-174.

HAdFiELd, J. D. (2010). MCMC methods for milti-response generalized linear mixed models: the MCMCglmm R package. Fournal of Statistical Software 33(2), 1-22.

Hadfield, J. D. \& Nakagawa, S. (2010). General quantitative genetic methods for comparative biology: phylogenies, taxonomies and multi-trait models for continuous and categorical characters. Fournal of Evolutionary Biology 23(3), 494-508.

Hall, M. D., Bussiere, L. F., Hunt, J. \& Brooks, R. (2008). Experimental evidence that sexual conflict influences the opportunity, form and intensity of sexual selection. Evolution 62(9), 2305-2315.

Hazel, J. R. \& Williams, E. E. (1990). The role of alterations in membrane lipid composition in enabling physiological adaptation of organisms to their physical environment. Progress in Lipid Research 29, 167-227.

Hebets, E. A., Wesson, J. \& Shamble, P. S. (2008). Diet influences mate choice selectivity in adult female wolf spiders. Animal Behaviour 76(2), 355-363.

Hedhly, A., Hormaza, J. I. \& Herrero, M. A. (2009). Global warming and sexual plant reproduction. Trends in Plant Science 14(1), 30-36.

Hetem, R. S., Fuller, A., Maloney, S. K. \& Mitchell, D. (2014). Responses of large mammals to climate change. Temperature $\mathbf{1}(2), 115-127$.

Higgins, J. P. \& Thompson, S. G. (2002). Quantifying heterogeneity in a meta-analysis. Statistics in Medicine 21(11), 1539-1558.

Hoffmann, A. A. \& SGro, C. M. (2011). Climate change and evolutionary adaptation. Nature 470, 479-485.

Holland, B. \& Rice, W. R. (1999). Experimental removal of sexual selection reverses intersexual antagonistic coevolution and removes a reproductive load. Proceedings of the National Academy of Sciences of the United States of America 96, 5083-5088.

Holman, L. \& Jacomb, F. (2017). The effects of stress and sex on selection, genetic covariance, and the evolutionary response. Fournal of Evolutionary Biology 30(10), 1898-1909.

House, C. M., Lewis, Z., Hodgson, D. J., Wedell, N., Sharma, M. D., Hunt, J. \& Hosken, D. J. (2013). Sexual and natural selection both influence male genital evolution. PLoS One 8(5), e63807.

Huey, R. B., Hertz, P. E. \& Sinervo, B. (2003). Behavioral drive versus behavioral inertia in evolution: a null model approach. The American Naturalist 161, 357-366.

Hunt, J. \& Hosken, D. J. (2014). Genotype-by-Environment Interactions and Sexual Selection. John Wiley \& Sons, Ltd, Chichester.

Husby, A., Visser, M. E. \& Kruuk, L. E. (2011). Speeding up microevolution: the effects of increasing temperature on selection and genetic variance in a wild bird population. PLoS Biology 9(2), el000585.

IPCG (2014). Intergovernmental Panel on Climate Change (IPCC), Climate Change 2014: Synthesis Report. IPCC, Geneva.

IsAAC, J. L. (2009). Effects of climate change on life history: implications for extinction risk in mammals. Endangered Species Research 7(2), 115-123.

Janicke, T., Haderer, I. K., Lajeunesse, M. J. \& Anthes, N. (2016). Darwinian sex roles confirmed across the animal kingdom. Science Advances 2(2), e1500983.

Janicke, T., Ritchie, M. G., Morrow, E. H. \& Marie-Orleach, L. (2018). Sexual selection predicts species richness across the animal kingdom. Proceedings of the Royal Society B: Biological Science 285(1878), 20180173.

Jarzebowska, M. \& RadWAn, J. (2010). Sexual selection counteracts extinction in small populations of bulb mites. Evolution 64(5), 1283-1289.

Jenkins, T. G., Aston, K. I., James, E. R. \& Carrell, D. T. (2017). Sperm epigenetics in the study of male fertility, offspring health, and potential clinical applications. Systems Biology in Reproductive Medicine 63(2), 69-76.

Jensen, L. F., Hansen, M. M., Pertoldi, C., Holdensgaard, G., Mensberg, K.-L. D. \& Loeschcke, V. (2008). Local adaptation in brown trout early life-history traits: implications for climate change adaptability. Proceedings of the Royal Society B: Biological Sciences 275(1653), 20082859. 
Jia, F. Y., Greenfield, M. D. \& Collins, R. D. (2000). Genetic variance of sexually selected traits in waxmoths: maintenance by genotype $\mathrm{x}$ environment interaction. Evolution 54(3), 953-967.

Jiao, X., Wu, J., Chen, Z., Chen, J. \& Liu, F. (2009). Effects of temperature on courtship and copulatory behaviours of a wolf spider Pardosa astrigera (Araneae: Lycosidae). Fournal of Thermal Biology 34(7), 348-352.

KATSUKI, M. \& MiYATAKe, T. (2009). Effects of temperature on mating duration, sperm transfer and remating frequency in Callosobruchus chinensis. Fournal of Insect Physiology $\mathbf{5 5}$ (2), 112-115.

Kearney, M., Simpson, S. J., Raubenheimer, D. \& Helmuth, B. (2010). Modelling the ecological niche from functional traits. Philosophical Transactions of the Royal Society B: Biological Sciences 365(1557), 3469-3483.

Ketola, T., Kristensen, T. N., Kellermann, V. M. \& Loeschcke, V. (2012). Can evolution of sexual dimorphism be triggered by developmental temperatures? Fournal of Evolutionary Biology 25(5), 847-855.

Kingsolver, J. G. \& Buckley, L. B. (2017). Evolution of plasticity and adaptive responses to climate change along climate gradients. Proceedings of the Royal Society B: Biological Sciences 284(1860), 20170386.

Klosin, A., Casas, E., Hidalgo-Carcedo, C., Vavouri, T. \& Lehner, B. (2017). Transgenerational transmission of environmental information in C. elegans. Science 356(6335), 320-323.

Кокко, H. \& Jennions, M. D. (2008). Parental investment, sexual selection and sex ratios. Fournal of Evolutionary Biology 21(4), 919-948.

Kокко, H. \& Rankin, D. J. (2006). Lonely hearts or sex in the city? Density-dependent effects in mating systems. Philosophical Transacrions of the Royal Society of London B Biological Science 361(1466), 319-334.

Kокко, H., Klug, H. \& Jennions, M. D. (2012). Unifying cornerstones of sexual selection: operational sex ratio, Bateman gradient and the scope for competitive investment. Ecology Letters 15(11), 1340-1351.

Kvarnemo, C. (1994). Temperature differentially affects male and female reproductive rates in the sand goby: consequences for operational sex ratio. Proceedings of the Royal Society of London. Series B: Biological Sciences 256(1346), 151-156.

Kvarnemo, C. (1996). Temperature affects operational sex ratio and intensity of malemale competition: an experimental study of sand gobies, Pomatoschistus minutus. Behavioral Ecology 7(2), 208-212.

KVARnemo, C. (1998). Temperature modulates competitive behaviour: why sand goby males fight more in warmer water. Ethology Ecology \& Evolution 10(2), 105-114.

LANDE, R. (1980). Sexual dimorphism, sexual selection, and adaptation in polygenic characters. Evolution 34(2), 292-305.

Le Galliard, J. F., Fitze, P. S., Ferriäre, R. \& Clobert, J. (2005). Sex ratio bias, male aggression, and population collapse in lizards. Proceedings of the National Academy of Sciences of the United States of America 102(50), 18231-18236.

Le Galliard, J. F., Massot, M., Landys, M. M., Meylan, S. \& Clobert, J. (2006). Ontogenic sources of variation in sexual size dimorphism in a viviparous lizard. Fournal of Evolutionary Biology 19(3), 690-704.

Levins, R. (1968). Evolution in Changing Environments. Princeton University Press, Princeton.

Liberati, A., Altman, D. G., Tetzlaff, J., Mulrow, C., GÃ̃tzsche, P. C., Ioannidis, J. P. A., Clarke, M., Devereaux, P. J., Klejjnen, J. \& Moher, D. (2009). The PRISMA statement for reporting systematic reviews and metaanalyses of studies that evaluate health care interventions: explanation and elaboration. PLoS Medicine 6(7), e1000100.

Lieshout, E., Tomkins, J. L. \& Simmons, L. W. (2013). Heat stress but not inbreeding affects offensive sperm competitiveness in Callosobruchus maculatus. Ecology and Evolution 3(9), 2859-2866.

Lindmark, M., Huss, M., Ohlberger, J. \& Gardmark, A. (2018). Temperaturedependent body size effects determine population responses to climate warming. Ecology Letters 21(2), 181-189.

Linn, C. E., Campbell, M. G. \& Roelofs, W. L. (1988). Temperature modulation of behavioural thresholds controlling male moth sex pheromone response specificity. Physiological Entomology 13(1), 59-67.

Llusia, D., Marquez, R., Beltran, J. F., Benitez, M. \& do Amaral, J. P. (2013). Calling behaviour under climate change: geographical and seasonal variation of calling temperatures in ectotherms. Global Change Biology 19(9), 2655-2674.

LONG, T. A. F., Agrawal, A. F. \& Rowe, L. (2012). The effect of sexual selection on offspring fitness depends on the nature of genetic variation. Current Biology 22(3), 204-208.

Lorch, P. D., Proulx, S., Rowe, L. \& Day, T. (2003). Condition-dependent sexual selection can accelerate adaptation. Evolutionary Ecology Research 5, 867-881.

Lumley, A. J., Michalczyk, L., Kitson, J. J., Spurgin, L. G., Morrison, C. A., Godwin, J. L., Dickinson, M. E., Martin, O. Y., Emerson, B. C., Chapman, T. \& GAGE, M. J. (2015). Sexual selection protects against extinction. Nature 522, 470-473.

MaAn, M. E. \& SeEhausen, O. (2011). Ecology, sexual selection and speciation. Ecology Letters 14(6), 591-602.

Machado, G., Buzatto, B. A., Garcia-Hernandez, S. \& Macias-Ordonez, R. (2016). Macroecology of sexual selection: a predictive conceptual framework for large-scale variation in reproductive traits. The American Naturalist 188(Suppl 1), S8-S27.
Martin, T. L. \& HueY, R. B. (2008). Why "suboptimal" is optimal: Jensen's inequality and ectotherm thermal preferences. The American Naturalist 171(3), E102-E118.

Martinez-Padilla, J., Estrada, A., Early, R. \& Garcia-Gonzalez, F. (2017). Evolvability meets biogeography: evolutionary potential decreases at high and low environmental favourability. Proceedings of the Royal Society B: Biological Sciences $\mathbf{2 8 4}$ (1856), 20170516

Martinez-Ruiz, C. \& Knell, R. J. (2017). Sexual selection can both increase and decrease extinction probability: reconciling demographic and evolutionary factors. fournal of Animal Ecology 86(1), 117-127.

Martinossi-Allibert, I., Arngvist, G. \& Berger, D. (2017). Sex-specific selection under environmental stress in seed beetles. Fournal of Evolutionary Biology 30(1), $161-173$.

Martinossi-Allibert, I., SAvkovic, U., Dordevic, M., Arnqvist, G., Stojkovic, B. \& Berger, D. (2018). The consequences of sexual selection in well-adapted and maladapted populations of bean beetles. Evolution 72(3), 518-530.

Martinossi-Allibert, I., Rueffler, C., Arngvist, G. \& Berger, D. (2019a). The efficacy of good genes sexual selection under environmental change. Proceedings of the Royal Society B: Biological Sciences 286(1896), 20182313.

Martinossi-Allibert, I., Thilliez, E., Arnovist, G. \& Berger, D. (2019b). Sexual selection, environmental robustness, and evolutionary demography of maladapted populations: a test using experimental evolution in seed beetles. Evolutionary Applications 12(7), 1371-1384.

Mazer, S. J., Hendrickson, B. T., Chellew, J. P., Kim, L. J., Liu, J. W., Shu, J. \& Sharma, M. V. (2018). Divergence in pollen performance between Clarkia sister species with contrasting mating systems supports predictions of sexual selection. Evolution 72(3), 453-472.

*McCabe, J. \& Partridge, L. (1997). An interaction between environmental temperature and genetic variation for body size for the fitness of adult female Drosophila melanogaster. Evolution 51, 1164-1174.

McDonald, G. C. \& Pizzari, T. (2018). Structure of sexual networks determines the operation of sexual selection. Proceedings of the National Academy of Sciences of the United States of America 115(1), E53-E61.

McDonald, G. C., James, R., Krause, J. \& Pizzari, T. (2013). Sexual networks: measuring sexual selection in structured, polyandrous populations. Philosophical Transaction of the Royal Society of London B: Biological Sciences 368(1613), 20120356.

McDonald, G. C., Spurgin, L. G., Fairfield, E. A., Richardson, D. S. \& Pizzari, T. (2019). Differential female sociality is linked with the fine-scale structure of sexual interactions in replicate groups of red junglefowl, Gallus gallus. Proceedings of the Royal Society B: Biological Sciences 286(1913), 20191734.

*Mehlis, M. \& Bakker, T. C. M. (2014). The influence of ambient water temperature on sperm performance and fertilization success in three-spined sticklebacks (Gasterosteus aculeatus). Evolutionary Ecology 28, 655-667.

Miller, C. W. \& Svensson, E. I. (2014). Sexual selection in complex environments. Annual Review of Entomology 59, 427-445.

Miller, D., Brinkworth, M. \& Iles, D. (2010). Paternal DNA packaging in spermatozoa: more than the sum of its parts? DNA, histones, protamines and epigenetics. Reproduction 139(2), 287-301.

Mills, S. C., Grapputo, A., Jokinen, I., Koskela, E., Mappes, T. \& Poikonen, T. (2010). Fitness trade-offs mediated by immunosuppression costs in a small mammal. Evolution 64(1), 166-179.

Moller, A. P. (2004). Protandry, sexual selection and climate change. Global Change Biology 10(12), 2028-2035.

Monteiro, N. M. \& Lyons, D. O. (2012). Stronger sexual selection in warmer waters: the case of a sex role reversed pipefish. PLoS One 7(8), e44251.

Monteiro, N., Cunha, M., Ferreira, L., Vieira, N., Antunes, A., Lyons, D. \& Jones, A. G. (2017). Parabolic variation in sexual selection intensity across the range of a cold-water pipefish: implications for susceptibility to climate change. Global Change Biology 23(9), 3600-3609.

Moore, M. P., Lis, C., Gherghel, I. \& Martin, R. A. (2019). Temperature shapes the costs, benefits and geographic diversification of sexual coloration in a dragonfly. Ecology Letters 22(3), 437-446.

Morimoto, J., McDonald, G. C., Smith, E., Smith, D. T., Perry, J. C., Chapman, T. Pizzari, T. \& Wigby, S. (2019). Sex peptide receptor-regulated polyandry modulates the balance of pre- and post-copulatory sexual selection in Drosophila. Nature Communications 10(1), 283

Morrissey, M. B. (2016). Meta-analysis of magnitudes, differences and variation in evolutionary parameters. Fournal of Evolutionary Biology 29(10), 1882-1904.

Moya-Laraño, J., El-Sayyid, M. E. T. \& Fox, C. W. (2007). Smaller beetles are better scramble competitors at cooler temperatures. Biology Letters 3(5), 475-478.

Murcia, C. (1990). Effect of floral morphology and temperature on pollen receipt and removal in Ipomoea trichocarpa. Ecology 71(3), 1098-1109.

Nakagawa, S. \& Santos, E. S. A. (2012). Methodological issues and advances in biological meta-analysis. Evolutionary Ecology 26(5), 1253-1274.

Nakagawa, S., Poulin, R., Mengersen, K., Reinhold, K., Engqvist, L., Lagisz, M. \& SENIOR, A. M. (2015). Meta-analysis of variation: ecological and evolutionary applications and beyond. Methods in Ecology and Evolution 6(2), 143-152. 
Narraway, C., Hunt, J., Wedell, N. \& Hosken, D. J. (2010). Genotype-byenvironment interactions for female preference. Fournal of Evolutionary Biology 23(12), 2550-2557.

Newman, J. A. (2003). Climate change and cereal aphids: the relative effects of increasing $\mathrm{CO}_{2}$ and temperature on aphid population dynamics. Global Change Biology 10, 5-15.

*Nguyen, T. M., Bressac, C. \& Chevrier, C. (2013). Heat stress affects male reproduction in a parasitoid wasp. Fournal of Insect Physiology 59, 248-254.

Nielsen, A., Reitan, T., Rinvoll, A. W. \& Brysting, A. K. (2017). Effects of competition and climate on a crop pollinator community. Agriculture, Ecosystems $\Xi^{\circ}$ Environment 246, 253-260.

Noble, D. W. A., Lagisz, M., O’Dea, R. E. \& Nakagawa, S. (2017a). Nonindependence and sensitivity analyses in ecological and evolutionary metaanalyses. Molecular Ecology 26(9), 2410-2425.

Noble, D. W. A., Stenhouse, V. \& Schwanz, L. E. (2017b). Developmental temperatures and phenotypic plasticity in reptiles: a systematic review and metaanalysis. Biological Reviewes 93(1), 72-97.

Noble, D. W. A., Radersma, R. \& Uller, T. (2019). Plastic responses to novel environments are biased towards phenotype dimensions with high additive genetic variation. Proceedings of the National Academy of Sciences of the United States of America 116 (27), 13452-13461.

Nunney, L. \& Cheung, W. (1997). The effect of temperature on body size and fecundity in female Drosophila melanogaster: evidence for adaptive plasticity. Evolution 51(5), 1529-1535.

Olsson, M., Wapstra, E., Schwartz, T., Madsen, T., Ujvari, B. \& Uller, T. (2011). In hot pursuit: fluctuating mating system and sexual selection in sand lizards. Evolution 65(2), 574-583.

PAERL, H. W. \& PAUL, V.J. (2012). Climate change: links to global expansion of harmful cyanobacteria. Water Research 46(5), 1349-1363.

Parker, G. A. \& Partridge, L. (1998). Sexual conflict and speciation. Philosophical Transactions of the Royal Society of London B: Biological Sciences 353(1366), 261-274.

Parmesan, C. (2006). Ecological and evolutionary responses to recent climate change. Annual Review of Ecology, Evolution, and Systematics 37(1), 637-669.

Parrett, J. M. \& Knell, R. J. (2018). The effect of sexual selection on adaptation and extinction under increasing temperatures. Proceedings of the Royal Society of London B: Biological Sciences 285(1877), 20180303

Parrett, J. M., Mann, D. J., Chung, A. Y. C., Slade, E. M. \& Knell, R. J. (2019). Sexual selection predicts the persistence of populations within altered environments. Ecology Letters 22(10), 1629-1637.

Pener, M. P. (1992). Environmental cues, endocrine factors, and reproductive diapause in male insects. Chronobiology International 9(2), 102-113.

Perry, J. C. \& Rowe, L. (2018). Sexual conflict in its ecological setting. Philosophical Transactions of the Royal Society of London B: Biological Sciences 373(1757), 20170418.

Perry, J. C., Sirot, L. \& Wigby, S. (2013). The seminal symphony: how to compose an ejaculate. Trends in Ecology and Evolution 28(7), 414-422.

Perry, J. C., Garroway, C. J. \& Rowe, L. (2017). The role of ecology, neutral processes and antagonistic coevolution in an apparent sexual arms race. Ecology Letters 20(9), 1107-1117.

Pick, J. L., Nakagawa, S. \& Noble, D. W. A. (2018). Reproducible, flexible and highthroughput data extraction from primary literature: the metaDigitise $\mathrm{R}$ package. Methods in Ecology \& Evolution 10(3), 426-431.

Pitnick, S. \& Garcia-GonZalez, F. (2002). Harm to females increases with male body size in Drosophila melanogaster. Proceedings of the Royal Society of London. Series B: Biological Sciences 269(1502), 1821-1828.

Pizzari, T., Biernaskie, J. M. \& Carazo, P. (2015). Inclusive fitness and sexual conflict: how population structure might modulate the battle of the sexes. BioEssays 37, 155-166.

Plesnar-Bielak, A., Skrzynecka, A. M., Prokop, Z. M. \& Radwan, J. (2012). Mating system affects population performance and extinction risk under environmental challenge. Proceedings of the Royal Society B: Biological Sciences 279(1747), 4661-4667.

Plesnar-Bielak, A., Skwierzynska, A. M., Hlebowicz, K. \& Radwan, J. (2018). Relative costs and benefits of alternative reproductive phenotypes at different temperatures - genotype-by-environment interactions in a sexually selected trait. BMC Evolutionary Biology 18, 109.

*Polak, M. \& Tomkins, J. L. (2012). Developmental instability as phenodeviance in a secondary sexual trait increases sharply with thermal stress. Fournal of Evolutionary Biology 25, 277-287.

Pomiankowski, A. \& Moller, A. (1995). A resolution of the lek paradox. Proceedings of the Royal Society of London. Series B: Biological Sciences 260(1357), 21-29.

Punzalan, D., Rodd, F. H. \& Rowe, L. (2008). Sexual selection mediated by the thermoregulatory effects of male colour pattern in the ambush bug Phymata americana. Proceedings of the Royal Society of London B: Biological Sciences 275(1634), 483-492.

Punzalan, D., Rodd, F. H. \& Rowe, L. (2010). Temporally variable multivariate sexual selection on sexually dimorphic traits in a wild insect population. The American Naturalist 175(4), 401-414.
Punzalan, D., Delcourt, M. \& Rundle, H. D. (2014). Comparing the intersex genetic correlation for fitness across novel environments in the fruit fly, Drosophila serrata. Heredity 112(2), 143-148.

RADWAN, J. (2004). Effectiveness of sexual selection in removing mutations induced with ionizing radiation. Ecology Letters 7(12), 1149-1154.

*Reeve, M. W., Fowler, K. \& Partridge, L. (2000). Increased body size confers greater fitness at lower experimental temperature in male Drosophila melanogaster. Fournal of Evolutionary Biology 13, 836-844.

Reinhardt, K., Dobler, R. \& Аввоtт, J. (2015). An ecology of sperm: sperm diversification by natural selection. Annual Review of Ecology, Evolution, and Systematics 46(1), 435-459.

RICE, W. R. (1984). Sex chromosomes and the evolution of sexual dimorphism. Evolution 38(4), 735-742.

RICE, W. R. (1996). Sexually antagonistic male adaptation triggered by experimental arrest of female evolution. Nature 381(6579), 232-234.

Rice, W. R. (1998). Intergenomic conflict, interlocus antagonistic coevolution, and the evolution of reproductive isolation. In Endless Forms: Species and Speciation (ed. D. J. Howard). Oxford University Press, New York.

Rice, W. R. \& Chippindale, A. K. (2002). The evolution of hybrid infertility: perpetual coevolution between gender-specific and sexually antagonistic genes. Genetica 116(2), 179-188.

Ritchie, M. G., SaArikettu, M., Livingstone, S. \& Hoikkala, A. (2001). Characterization of female preference functions for Drosophila montana courtship song and a test of the temperature coupling hypothesis. Evolution 55(4), 721-727.

Robinson, M. R., van Doorn, G. S., Gustafsson, L. \& Qvarnstrom, A. (2012). Environment-dependent selection on mate choice in a natural population of birds. Ecology Letters 15(6), 611-618.

Rogell, B., Widegren, W., Hallsson, L. R., Berger, D., Björklund, M., Makl_akov, A. A. \& Fox, C. (2014). Sex-dependent evolution of life-history traits following adaptation to climate warming. Functional Ecology 28(2), 469-478.

Rohr, J. R., Civitello, D. J., Cohen, J. M., Roznik, E. A., Sinervo, B. \& Dell, A. I. (2018). The complex drivers of thermal acclimation and breadth in ectotherms. Ecology Letters 21(9), 1425-1439.

Rowe, L. \& Houle, D. (1996). The lek paradox and the capture of genetic variance by condition dependent traits. Proceedings of the Royal Society of London. Series B: Biological Sciences 263(1375), 1415-1421.

Rowe, L., Arnqvist, G., Sih, A. \& Krupa, J. J. (1994). Sexual conflict and the evolutionary ecology of mating patterns: water striders as a model system. Trends in Ecology and Evolution 9(8), 289-293.

Sales, K., Vasudeva, R., Dickinson, M. E., Godwin, J. L., Lumley, A. J., Michalczyk, Å. U., Hebberecht, L., Thomas, P., Franco, A. \& Gage, M. J. G. (2018). Experimental heatwaves compromise sperm function and cause transgenerational damage in a model insect. Nature Communications 9(1), 4771.

*SAmbucetti, P. \& Norry, F. M. (2015). Mating success at high temperature in highland- and lowland-derived populations as well as in heat knock-down selected Drosophila buzzatii. Entomologia Experimentalis et Applicata 154, 206-212.

SAntos, M. R., Vieira, N. \& Monteiro, N. M. (2018). High temperatures disrupt Artemia franciscana mating patterns and impact sexual selection intensity. Estuarine, Coastal and Shelf Science 207, 209-214.

*SAXon, A. D., O'Brien, E. K. \& BridLe, J. R. (2018). Temperature fluctuations during development reduce male fitness and may limit adaptive potential in tropical rainforest Drosophila. Fournal of Evolutionary Biology 31, 405-415.

Schuster, S. M. \& Wade, M. J. (2003). Mating Systems and Strategies. Princeton University Press, Princeton.

Seebacher, F., White, C. R. \& Franklin, C. E. (2014). Physiological plasticity increases resilience of ectothermic animals to climate change. Nature Climate Change 5, 61-66.

Seehausen, O., Alphen, J. J. M. V. \& Witte, F. (1997). Cichlid fish diversity threatened by eutrophication that curbs sexual selection. Science 277(5333), 1808-1811.

Sentis, A., Ramon-Portugal, F., Brodeur, J. \& Hemptinne, J. L. (2015). The smell of change: warming affects species interactions mediated by chemical information. Global Change Biology 21(10), 3586-3594.

Sgro, C.,. M. \& Hoffmann, A. A. (2002). Effects of temperature extremes on genetic variances for life history traits in Drosophila melanogaster as determined from parentoffspring comparisons. Fournal of Evolutionary Biology 11(1), 1-20.

Sheriff, M. J., Kenagy, G. J., Richter, M., Lee, T., Toien, O., Kohl, F., Buck, C. L. \& Barnes, B. M. (2011). Phenological variation in annual timing of hibernation and breeding in nearby populations of Arctic ground squirrels. Proceedings of the Royal Society B: Biological Sciences 278(1716), 2369-2375.

Silva, K., Vieira, M. N., Almada, V. C. \& Monteiro, N. M. (2007). The effect of temperature on mate preferences and female-female interactions in Syngnathus abaster. Animal Behaviour 74(5), 1525-1533.

Simmons, L. W. \& EmLEn, D. J. (2006). Evolutionary trade-off between weapons and testes. Proceedings of the National Academy of Sciences of the United States of America 103(44), 16346-16351.

Simmons, L. W. \& RoberTs, B. (2005). Bacterial immunity traded for sperm viability in male crickets. Science 309(5743), 2031. 
SLATKIN, M. (1974). Hedging one's evolutionary bets. Nature 250(5469), 704-705. Snell-Rood, E. C., Van Dyken, J. D., Cruickshank, T., Wade, M. J. \& Moczek, A. P. (2010). Toward a population genetic framework of developmental evolution: the costs, limits, and consequences of phenotypic plasticity. BioEssays 32(1), 71-81.

Stillwell, R. C. \& Fox, C. W. (2007). Environmental effects on sexual size dimorphism of a seed-feeding beetle. Oecologia 153(2), 273-280.

Stillwell, R. C., Blanckenhorn, W. U., Teder, T., Davidowitz, G. \& Fox, C. W. (2010). Sex differences in phenotypic plasticity affect variation in sexual size dimorphism in insects: from physiology to evolution. Annual Review of Entomology 55, 227-245.

Stone, G. N. (1994). Activity patterns of females of the solitary bee Anthophora plumipes in relation to temperature, nectar supplies and body size. Ecological Entomology 19, 177-189.

Stuppia, L., Franzago, M., Ballerini, P., Gatta, V. \& Antonucci, I. (2015). Epigenetics and male reproduction: the consequences of paternal lifestyle on fertility, embryo development, and children lifetime health. Clinical Epigenetics 7, 120.

Sundin, I., Aronsen, T., Rosenovist, G. \& Berglund, A. (2017). Sex in murky waters: algal-induced turbidity increases sexual selection in pipefish. Behavioral Ecology and Sociobiology 71(5), 78.

Suzaki, Y., Kodera, S., Fujimara, H., Sasaki, R., Okada, K. \& Katsuki, M. (2018). Temperature variations affect postcopulatory but not precopulatory sexual selection in the cigarette beetle. Animal Behaviour 144, 115-123.

Svensson, E. I. (2019). Eco-evolutionary dynamics of sexual selection and sexual conflict. Functional Ecology 33, 60-72.

Svensson, E. I., Willink, B., Duryea, M. C. \& Lancaster, L. T. (2020). Temperature drives pre-reproductive selection and shapes the biogeography of a female polymorphism. Ecology Letters 23(1), 149-159.

Travers, S. E. \& ShEA, K. (2001). Individual variation, gematophytic compatition and style length: does size affect paternity? Evolutionary Ecology Research 3, 729-745.

*Tregenza, T., Wedell, N., Hosken, D. J. \& Wards, P. I. (2003). Maternal effects on offspring depend on female mating pattern and offspring environment in yellow dung flies. Evolution 57, 297-304.

Twiss, S. D., Thomas, C., Poland, V., Graves, J. A. \& Pomeroy, P. (2007). The impact of climatic variation on the opportunity for sexual selection. Biology Letters 3(1), 12-15.

Vanpa, C., KJellander, P., Galan, M., Cosson, J.-F., Aulagnier, S., Liberg, O. \& Hewison, A. J. M. (2008). Mating system, sexual dimorphism, and the opportunity for sexual selection in a territorial ungulate. Behavioral Ecology 19(2), 309-316.

VAsudeva, R., Deeming, D. C. \& EAdY, P. E. (2014). Developmental temperature affects the expression of ejaculatory traits and the outcome of sperm competition in Callosobruchus maculatus. Fournal of Evolutionary Biology 27(9), 1811-1818.

VAtKa, E., Orell, M. \& RYtKönEn, S. (2011). Warming climate advances breeding and improves synchrony of food demand and food availability in a boreal passerine. Global Change Biology 17(9), 3002-3009.

Viechtbauer, W. (2010). Conducting meta-analyses in R with the metafor package. fournal of Statistical Software 36(3), 1-48.
Walker, T. J. (1957). Specificity in the response of female tree crickets (Orthoptera, Gryllidae, Oecanthinae) to calling songs of the males. Annals of the Entomological Socciety of America 50, 626-636.

Walsh, B. S., Parratt, S. R., Hoffmann, A. A., Atkinson, D., Snook, R. R., Bretman, A. \& Price, T. A. R. (2019). The impact of climate change on fertility. Trends in Ecology and Evolution 34(3), 249-259.

WANG, Y., Liu, H. \& Sun, Z. (2017). Lamarck rises from his grave: parental environment-induced epigenetic inheritance in model organisms and humans. Biological Reviews 92(4), 2084-2111.

WArner, D. A., Lovern, M. B. \& Shine, R. (2007). Maternal nutrition affect reproductive output and sex allocation in a lizard with environmental sex determination. Proceedings of the Royal Society B: Biological Sciences 274(1611), 883-890.

West, P. M. \& Packer, C. (2002). Sexual selection, temperature and the Lion's mane. Science 297, 1339-1343.

West-Eberhard, M. J. (2003). Developmental Plasticity and Evolution. Oxford University Press, New York.

Whitlock, M. C. \& Agrawal, A. F. (2009). Purging the genome with sexual selection: reducing mutation load though selection on males. Evolution 63(3), 569-582.

Wigby, S. \& Chapman, T. (2004). Female resistance to male harm evolves in response to manipulation of sexual conflict. Evolution 58, 1028-1037.

*Wilson, R. S. (2005). Temperature influences the coercive mating and swimming performance of male eastern mosquitofish. Animal Behaviour 70, 1387-1394.

YASUi, Y. \& GARCiA-GonZALEZ, F. (2016). Bet-hedging as a mechanism for the evolution of polyandry, revisited. Evolution 70(2), 385-397.

*Yenisetti, S. C., Hegde, S. N., Venkateswarlu, M. \& Krishna, M. S. (2006) Phenotypic plasticity of sexual behavior at different temperatures in a drosophilid: Phorticella striata. Korean Fournal of Genetics 28, 395-401.

Zajitschek, S. R. K., Dowling, D. K., Head, M. L., Rodriguez-Exposito, E. \& Garcia-Gonzalez, F. (2018). Transgenerational effects of maternal sexual interactions in seed beetles. Heredity 121, 282-291.

\section{Supporting information}

Additional supporting information may be found online in the Supporting Information section at the end of the article. Appendix S1. Meta-analysis on the effects of temperature on sexual selection.

Table S1. Final sample of studies (and extracted effect sizes) used in the meta-analysis.

(Received 31 October 2019; revised 10 June 2020; accepted 12 June 2020; published online 20 July 2020) 